RÚIZ GARCÍA, M.J., «El panel de mediadores: un recurso para la mediación intrajudicial», REDUR 17, diciembre 2019, págs. 205-236. ISSN 1695-078X. doi: 10.18172/redur.4495

\title{
EL PANEL DE MEDIADORES: UN RECURSO PARA LA MEDIACIÓN INTRAJUDICIAL
}

\author{
MARÍA JOSÉ RUIZ GARCÍA \\ Mediadora en el Defensor del Pueblo AndaluZ, Abogada y Profa. De Derecho Civil De la Universidad \\ DE HUELVA \\ mariajose@mediantes.com
}

SUMARIO: I. INTRODUCCIÓN. II. ELEMENTOS BÁSICOS EN LA MEDIACIÓN INTRAJUDICIAL. II.1. EL ÓRGANO JUDICIAL. II.2 LOS MEdiadores: El PANEL INTRAJUdiCIAL. II.3. DESTINATARIOS. III. SELECCIÓN DE CASOS QUE PUEDEN DERIVARSE A MEDIACIÓN. III.1. COMPETENCIA PARA REALIZAR LA SELECCIÓN. III.2. ASUNTOS SUSCEPTIBLES DE SER DERIVADOS A MEDIACIÓN. IV. INFORMACIÓN DE MEDIACIÓN Y DERIVACIÓN A SESIÓN INFORMATIVA DE MEDIACIÓN. IV.1. RESOLUCIÓN DEL JUZGADO. IV.2. MOMENTO DE LA DERIVACIÓN. IV.3. SISTEMA DE DERIVACIÓN. V. COSTE DE LA MEDIACIÓN INTRAJUDICIAL. VI. DESARROLLO DE LA MEDIACIÓN INTRAJUDICIAL. VI.1. SESIÓN INFORMATIVA. VI.2. INFORMACIÓN AL JUZGADO. VI.3. SESIONES DE MEDIACIÓN. VII. INCORPORACIÓN DEL RESULTADO AL PROCEDIMIENTO JUDICIAL. VIII. SISTEMA DE EVALUACIÓN Y CONTROL. IX. BIBLIOGRAFÍA. X. ANEXOS.

RESUMEN: La derivación a sesión informativa de mediación por los Tribunales de Justicia requiere la configuración de un panel de los profesionales de la mediación por partidos judiciales que facilite de forma inmediata el acceso a la información tanto a los tribunales como a los ciudadanos. Presentamos una propuesta de configuración de un panel de mediadores intrajudiciales que acompaña a una dinámica de derivación judicial a sesión informativa de mediación profesional, en el ámbito civil y mercantil conforme a las Guías para la Mediación publicadas por el Consejo General del Poder Judicial.

Palabras Clave: Mediación, Mediador intrajudicial, Mediadores, Instituciones de Mediación, Procesos de resolución de conflictos.

\section{A PANEL OF MEDIATORS \\ A RESOURCE FOR THE COURT MEDIATION SESSION}

ABSTRACT: Court referrals to an introductory mediation session require the configuration of a panel of mediation professionals by judicial districts to provide immediate access to information both to the courts and to citizens. We present a proposal for the configuration of a panel of court mediators for use by judges referring cases to professional mediation according to the Guidelines of the General Council of the Judicial Branch.

KEYWORDS: Mediation, Court mediators, Mediators, Mediation Institute, ADR. 


\section{Introducción}

La Ley 5/2012 de Mediación para asuntos civiles y mercantiles (en adelante LMACM), el Real Decreto 980/2013, de 13 de diciembre (en adelante, RD980/2013) que desarrolla determinados aspectos de la LMACM y las Guías para la práctica de la mediación intrajudicial publicadas por el CGPJ ${ }^{1}$, (en adelante, las Guías del CGPJ) permiten abrir un marco de actuación homogéneo en mediación intrajudicial, que potencia la profesionalidad e independencia de los mediadores. La configuración de un panel de mediadores e instituciones de mediación que intervengan en el ámbito intrajudicial, facilita a todos los operadores jurídicos -jueces, fiscales, letrados de la administración de justicia, oficina judicial, abogados, ciudadanos- una información ordenada de los profesionales de la mediación, ante la posibilidad legal de derivación ${ }^{2}$ a sesión informativa de mediación. Un panel de mediadores e instituciones de mediación, organizado por partido judicial, contribuiría a dar accesibilidad, apertura, visibilidad y transparencia a la introducción de la figura del mediador en los procesos judiciales. Formulamos una propuesta de configuración de estos paneles de mediadores partiendo de las Guías de CGPJ que acompaña a un protocolo de actuación para la derivación intrajudicial que ha tenido el informe favorable del Tribunal Superior de Justicia de Andalucía y del Consejo General del Poder Judicial. Tratamos de promover así un servicio profesional de mediación intrajudicial en los juzgados de ámbito civil y mercantil, adaptable a otras jurisdicciones.

En el ámbito intrajudicial, la mediación plantea complejidad. Por un lado, desde una perspectiva formal, requiere acoplarse al proceso judicial en curso. Y por otro, respecto al fondo material del asunto, ya existe una «conversación» entre las partes, de carácter confrontativa y basada en la ley. A pesar de ello, las experiencias de mediación intrajudicial avalan la oportunidad del recurso para girar la conversación hacia la colaboración en la resolución del asunto cuando resulte los más oportuno en interés de las partes. La profesionalidad del mediador resulta para ello una prioridad y una preocupación para las instituciones de mediación y para consolidar la confianza de los operadores jurídicos en la mediación.

Conforme al marco legal nacional de la mediación (LMACM, el RD 980/2013 y las modificaciones pertinentes en la Ley de Enjuiciamiento Civil), entendemos que la mediación intrajudicial debe ser desarrollada por mediadores que cumplan como mínimo, las exigencias legalmente previstas en dicho marco normativo³. Además, el RD 980/2013,

1 Guía para la práctica de la mediación intrajudicial del CGPJ, actualizada en Noviembre de 2016. http://www.poderjudicial.es/cgpj/es/Temas/Mediacion/Guia-para-la-practica-de-la-Mediacion-Intrajudicial/ [Consulta: 15 junio 2017]

2 La Ley de Enjuiciamiento Civil, otorga al letrado de la administración de justicia la facultad de informar, que puede ser documentalmente facilitando folletos o indicando puntos gratuitos establecidos en sede judicial de la mediación. Al juez le faculta a derivar en «atención al objeto del pleito» lo que implica una valoración por su parte. De existir configurado un panel de mediadores o instituciones de mediación podría hacerlo de la misma forma que procede a la designación de peritos o administradores concursales.

${ }^{3}$ Artículo 5 y 11 de la Ley 5/2012 MACM y Capitulo II del Real Decreto 980/2013 de 13 de diciembre que establece las necesidades formativas de los mediadores para poder realizar una mediación conforme a la Ley y obtener sus beneficios, como la elevación a público del acuerdo de mediación. Los mediadores pueden ser personas naturales en pleno ejercicio de sus derechos civiles, con título oficial universitario o de formación profesional superior y contar con formación específica en mediación a través de uno o varios cursos impartidos por instituciones acreditadas en la materia y tener suscrito además de un seguro de responsabilidad civil o 
facilita los medios al configurar, en su Capítulo III, un Registro de Mediadores e Instituciones de Mediación dependiente del Ministerio de Justicia, de carácter voluntario, -excepto para el mediador concursal-, que tiene por finalidad facilitar la publicidad de mediadores profesionales e instituciones de mediación ${ }^{4}$. En atención a este marco normativo y a los esfuerzos del CGPJ por impulsar la mediación, y sólo para la mediación intrajudicial, proponemos desde nuestra experiencia, ${ }^{5}$ la configuración de un panel de mediadores intrajudiciales que de forma profesional puedan desarrollar las funciones descritas en el artículo 17 de la LMACM, información y sesión informativa. A través de este panel de mediadores, se optimizan los recursos ofrecidos por el Ministerio de Justicia, para agilizar la derivación a sesión informativa al mediador designado por las partes y/o sus representantes, favoreciendo agilidad y atención directa, mayor inmediatez, profesionalidad, control de legalidad y acceso igualitario de los mediadores organizados por partidos judiciales y jurisdicciones. La información que facilitamos en este artículo responde a cómo poner en marcha la mediación intrajudicial.

\section{Elementos básicos de la mediación intrajudicial}

\section{II.1. El órgano judicial}

Desde la entrada en vigor de la LMACM y el RD 980/20136 que la desarrolla, los jueces de civil y mercantil de la capital de provincia y de los diferentes partidos judiciales que así lo estimen pueden derivar directamente asuntos a sesión informativa de mediación, en «atención al objeto del proceso»7. La invitación a sesión informativa de mediación procede siempre del juez, por iniciativa propia o a instancia de parte si así lo solicitan al

garantía equivalente (artículo 11 de la Ley 5/2012 MACM). El RD 980/2013 dedica el Capítulo II a la formación del mediador, estableciendo en el artículo 5 una formación mínima de 100 horas de docencia efectiva, estableciendo una formación continua mínima de 20 horas, al menos cada 5 años. En el artículo 4 especifica los contenidos y el tipo de formación exigidas a los mediadores para poder realizar mediaciones conforme a la ley. Además de establecer exigencias para los centros de formación en su artículo 7.

${ }^{4}$ Artículo 8 del RD 980/2013 establece el carácter público e informativo y se constituirá como una base de datos informatizada accesible a través del sitio web del Ministerio de Justicia. http://www.mjusticia.gob.es/cs/Satellite/Portal/es/areas-tematicas/registros/mediadores-instituciones [Consulta 18 junio 2017].

5 Creación de la Unidad de Mediación de la Universidad de Huelva, coordinación y ejecución de la experiencia piloto de mediación intrajudicial reconocida por el CGPJ durante los años 2009 a 2012 en el Juzgado de 1ํㅗ Instancia núm. 7 de Huelva.

6 https://www.boe.es/buscar/doc.php?id=BOE-A-2012-9112 http://www.boe.es/buscar/doc.php?id=BOEA-2013-13647. [Consulta 15 junio 2017]. ORTUÑO MUÑOZ, Pascual «A modo de conclusiones: la implantación de la mediación intrajudicial», en POMPEU CASANOVAS, Jaume M. y LAUROBA M Elena (Dirs.), Libro Blanco de la Mediación en Cataluña, Departament de Justicia de la Generalitat de Catalunya, Barcelona, 2011. MARTÍN NÁJERA, T., PÉREZ SALAZAR, M. y UTRERA GUTIERREZ, J.L., "Protocolo para la implantación de la mediación familiar intrajudicial en los juzgados y tribunales que conocen de procesos de familia", Revista de Mediación, Año 2, No 4, octubre 2009, p. 14

7 Párrafo cuarto del número 1 del artículo 414 introducido en su actual redacción por el apartado diez de la disposición final tercera de la LMACM [Consulta 15 junio 2017]. Sobre la función del juez al derivar a sesión informativa ALASTRUEY GRACIA, Raquel., «Argumentario sobre la búsqueda de soluciones negociadas en el proceso civil» p.3, disponible en http: www.poderjudicial.es. Nuestra propuesta puede adaptarse a otras jurisdicciones como la social y contencioso administrativo. 
juzgado. Por su parte el letrado de la Administración de Justicia puede en sus resoluciones informar de la existencia del recurso de la mediación. Las funciones de informar y derivar a sesión informativa se encuentran claramente distinguidas en el artículo 17 de la LMACM, no siendo una sustitutiva de la otra como indica el propio artículo y explicaremos más adelante.

\section{II.2 Los Mediadores: El panel intrajudicial}

La mediación intrajudicial puede realizarla un mediador que como mínimo, cumpla los requisitos exigidos en la LMACM, y en el RD 980/2013. Igualmente, los mediadores de las instituciones de mediación constituidas conforme al artículo 5 LMACM sean entidades o colegios profesionales. Entendemos que los mediadores del panel intrajudicial, deben estar inscritos en el Registro de Mediadores e Instituciones de Mediación del Ministerio de Justicia (LMACM y RD 980/2013), a pesar del carácter voluntario, salvo para el mediador concursal, pues como establece el apartado III del Preámbulo del DR 980/2013, «la regulación del Registro de Mediadores e Instituciones de mediación hace de él una pieza importante para reforzar la seguridad jurídica en este ámbito, en la medida que la inscripción en el mismo permitirá acreditar la condición de mediador, que plasmada en el acta inicial de una mediación será objeto de comprobación tanto por el notario que eleve a escritura pública el acuerdo de mediación como el juez que proceda a la homologación judicial de tales acuerdos». ${ }^{8}$ Si el mediador no está inscrito en el Registro de mediadores, el notario debe requerir la acreditación al mediador de las exigencias legales previstas en el artículo 11 de la LMACM y por tanto su concurrencia a la notaría, a pesar de ser innecesaria conforme al artículo 25.1 in fine de la LMACM. Dicho Registro cumple una función informativa, organizadora y de control formativo de estos profesionales. Si el mediador está inscrito en el Registro de Mediadores su indicación en el acuerdo, puede simplificar y agilizar al notario o al juez su obligación de control, que puede corrobora la información telemáticamente. La mediación intrajudicial se inicia, conforme al artículo 17.3 de la LMACM, cuando las partes voluntariamente inicien una mediación estando en curso un proceso judicial. Si las partes realizan la mediación y llegan a un acuerdo, el artículo 25.4 de la LMACM prevé la posibilidad que tienen las partes de solicitar al juez la homologación del acuerdo de mediación. Estamos en sede de formalización del título ejecutivo y las garantías exigidas para el acuerdo de mediación deben ser las mismas sea extrajudicial o intrajudicial, en lo que a las exigencias legales del mediador se refiere. El juez que derive un asunto a mediación, en su resolución, puede directamente indicar el Registro de Mediadores e Instituciones de mediación para que las partes o sus letrados designen mediador asegurando así que el profesional que la realiza, cumple con las exigencias mínimas legales. Cualquier persona puede acceder al Registro de Mediadores y de Instituciones de Mediación del Ministerio de Justicia ${ }^{9}$ para obtener la información de los mediadores inscritos. Y para

\footnotetext{
8 En consonancia con ello resultan los artículos 23 y 25.2 de la LMACM El primero regula el acuerdo de mediación estableciendo que dicho acuerdo debe hacer constar el ajuste de la mediación a las previsiones de la Ley, así como la identidad del mediador o mediadores, y, en su caso, institución de mediación que han intervenido. Y tras ello, el art 25.2 de la LMACM, para elevar a escritura pública el acuerdo de mediación, el Notario verificará el «cumplimiento de los requisitos exigidos en esta Ley». [Consulta 15 junio 2017]
}

${ }_{9}^{9} \mathrm{http}: / /$ www.mjusticia.gob.es/cs/Satellite/Portal/es/areas-tematicas/registros/mediadoresinstituciones. 
acercar información al usuario, al juez y al resto de los operadores jurídicos por partidos judiciales y jurisdicción, proponemos la creación de un panel de mediadores intrajudiciales e instituciones de mediación de carácter provincial, que disponga de la información ordenada de los profesionales de la mediación y de las instituciones de mediación que realicen mediación intrajudicial. Esto supondría una optimización de los recursos que proporciona mayor inmediatez ${ }^{10}$. Pudiendo además el CGPJ, darle publicidad por provincias y partidos judiciales a través de su web.

El panel intrajudicial incorporaría a los mediadores e instituciones de mediación que cumplan las exigencias previstas por LMACM y en el RD 980/2013 y que deseen participar en la derivación a sesión informativa de mediación una vez iniciado el procedimiento judicial. La exigencia de la inscripción en el Registro de Mediadores asegura el cumplimiento de las obligaciones mínimas formales del mediador, que el juez debe comprobar11. Finalmente la incorporación del mediador al servicio de mediación intrajudicial del partido judicial, debe ser aprobada por el decanato de jueces de la capital provincial y por la Presidencia de la Audiencia. Así los mediadores y las Instituciones de Mediación que pretendan acceder al panel de mediadores intrajudiciales, deben formular una solicitud ${ }^{12}$ (Anexo 1) para su inclusión en dicho panel, suscribir el protocolo de actuación establecido y aportar en cualquier caso:

\section{II.2.I. Los Mediadores}

a) Acreditar su inscripción en el Registro de Mediadores del Ministerio de Justicia ${ }^{13}$.

b) Curriculum vitae ${ }^{14}$ (Anexo 2) indicando: formación y experiencia profesional, y formación y experiencia teórica y práctica en Mediación. Ámbitos materiales de intervención en los que pretenda mediar, así como adscripción a programas de gratuidad si existiesen. También deben especificar su ámbito territorial por partidos judiciales en los que desee intervenir.

c) El mediador indicará en el curriculum vitae (Anexo 2), los siguientes extremos: jurisdicción, materias, partido judicial, en la que desee mediar y si muestra su conformidad a desarrollar de manera gratuita la mediación (no sólo la sesión informativa) en los supuestos en que los litigantes gocen del beneficio de Justicia Gratuita. Y en estos casos, informar de su participación o no, en algún programa donde la mediación es gratuita para los beneficiaros de ese derecho, y remunerada para el mediador. Por último, podrá indicar su voluntad de inclusión altruista para dar información de mediación en los puntos de Información de la mediación, que las

\footnotetext{
${ }^{10}$ De existir el panel, desde la oficina judicial se les puede facilitar el listado de mediadores a los letrados e interesados para la selección.

11 Como disponer de un seguro de responsabilidad civil y de una formación mínima y continua exigida en la LMACM y DR 980/22013. El Convenio suscrito entre el CGPJ y el Consejo General de la Abogacía de España, que establece entre los compromisos de las partes, cláusula 4을 letra b, punto 6, que los Colegios velarán por que los equipos de mediación incorporados a los Colegios de Abogados se compongan de profesionales mediadores que estén inscritos en el Registro de Mediadores del Ministerio de Justicia.

12 ANEXO 1. Solicitud acceso al panel, elaborado a tal efecto como ficha registro personal a enviar.

13 Podría admitirse la solicitud de inscripción dada la lentitud del proceso de inscripción en el Registro.

14 ANEXO 2 Modelo de CV.
} 
Comunidades Autónomas (en adelante, CCAA) tengan habilitados en sede judicial conforme a su acuerdo ${ }^{15}$ con el CGPJ, la disposición adicional segunda, y del artículo 17.2 de la LMACM.

\section{II.2.2. Las Instituciones de Mediación (entidades/colegios profesionales)}

a) Acreditar la inscripción de la institución/entidad/colegio profesional en el Registro de Instituciones de Mediación del Ministerio de Justicia.

b) En relación a los miembros de la institución/entidad/colegio profesional que quieran incorporarse al panel intrajudicial, deben aportar junto al listado remitido por la institución al Decanato (Presidencia de la Audiencia) los siguientes documentos:

b.1) Certificación individual de cada mediador relativa a su inscripción en el Registro de Mediadores o emitir certificación por parte de la institución/entidades/colegio profesional acreditativa de haber realizado la comprobación de la inscripción de los mediadores que incluye en el listado en el indicado Registro de Mediadores.

b.2) Curriculum vitae de cada uno de sus mediadores (Anexo 2) debidamente cumplimentado como indicamos anteriormente.

c) La institución/entidad/colegio profesional indicará el ámbito en el que puede desarrollar la mediación y en concreto se pronunciará, sobre los siguientes extremos: jurisdicción, materias, partido judicial, y si muestra su conformidad a desarrollar de manera gratuita la mediación (o sólo la sesión informativa) en los supuestos en que los litigantes gocen del beneficio de Justicia Gratuita, procediendo a especificar aquellos de sus mediadores comprometidos. También informará de cuales de sus mediadores participan en algún programa donde la mediación es gratuita para los beneficiaros de ese derecho, y remunerada para el mediador. Y dispondrá del listado de mediadores que muestren su interés en dar información de mediación en los puntos de información a la Mediación que la CCAA tengan habilitados conforme a su acuerdo con el CGPJ, la disposición adicional segunda y del art. 17.2 de la LMACM (Anexo 3) ${ }^{16}$.

Asimismo, las respectivas instituciones de mediación vigilarán y responderán del cumplimiento por sus mediadores de las exigencias legales mínimas formativas, incluida la efectiva formación continua ${ }^{17}$. El Decano o Presidente de la Audiencia Provincial pondrá en

\footnotetext{
15 Dicho acuerdo es para la «dotación de espacios, formación de empleados públicos y difusión del recurso entre otros, no siendo incompatible con la existencia de otras relaciones de colaboración en el ámbito de la mediación ni excluyente con cualquier otro convenio con institución o entidades de similar naturaleza». Cláusula undécima del convenio tipo del CGPJ, póngase de ejemplo el suscrito con Andalucía. http://www.juntadeandalucia.es/export/drupaljda/Convenio\%20de\%20colaboración\%20para\%20la\%20pro moción\%20de\%20la\%20mediación\%20(2).pdf [Consulta 5 junio 2017].

16 Anexo 3 Ficha de Instituciones que supone un filtro para la organización de la propia institución.

17 Al tratarse del desarrollo de habilidades específicas de comunicación y de gestión del conflicto, la experiencia acumulada y contrastada a través de los correspondientes controles de calidad, será igualmente valorada a la hora de renovar los paneles o listados de profesionales mediadores de las entidades mediadoras. FERNÁNDEZ MANZANO, M.L., «La calidad de los servicios de mediación: el compromiso ético de las entidades
} 
conocimiento del CGPJ la eventual exclusión del panel de aquéllos mediadores que no se desempeñen correctamente las funciones asumidas ${ }^{18}$.

Anualmente se publicará la relación nominal de quienes formen parte del panel, el ámbito territorial de actuación, la especialización o ámbito conflictual en el que se desempeñarán y los demás requerimientos exigidos. Existirá en las oficinas judiciales una ficha (Anexo 5) que recoge en panel de mediadores, que organiza toda la información exigida en este punto y que sirve de información directa desde los juzgados ${ }^{19}$. Sería recomendable que dicha información fuera facilitada al CGPJ a través de la Presidencia de la Audiencia, para su incorporación y difusión a través de su web ${ }^{20}$. La web del CGPJ tal y como se estructura ahora por provincias y jurisdicciones, podría incluir la información (anexo 5) de los paneles de mediadores intrajudiciales por partidos judiciales, creados según este protocolo, dando visibilidad, transparencia y acercando la información a cualquier interesado. La web del CGPJ puede hacer accesible los anexos a cumplimentar para forma parte del panel intrajudicial de mediadores y disponer así de toda la información de forma telemática.

La designación del mediador por la institución de mediación para el caso concreto, determinará la asunción de todas las normas fijadas, además de las propias de la profesión, código de buenas prácticas y especialmente el Código de conducta europeo de los mediadores.

Por último, la Directiva 2013/11/EU del Parlamento Europeo y del Consejo, de 21 de mayo de 2013 relativa a la resolución alternativa de litigios en materia de consumo, ya tiene un Proyecto de Ley ${ }^{21}$ que la incorpora al derecho interno. «Los consumidores residentes en España o en cualquier Estado miembro de la Unión Europea tendrán la posibilidad de resolver sus litigios de consumo con empresarios establecidos en España acudiendo a entidades de resolución alternativa de calidad que hayan sido acreditadas por la autoridad competente e incluidas en un listado nacional de entidades acreditadas, el cual será trasladado a la Comisión Europea para que sea incluido en el listado único de entidades

que los gestionan, la supervisión de la labor mediadora y la formación profesional de los mediadores, instrumentos clave para alcanzarla», comunicación presentada en el marco del III Simposio Tribunales y Mediación en España, celebrado en Madrid los días 26 y 27 de septiembre de 2013.Disponible en: http:// www.mediacio- nesjusticia.es. [Consulta: 15 junio 2017]

18 A lo largo de la LMACM se describen obligaciones del mediador respecto del proceso conforme a Ley, especialmente los artículos 14 y 21. Además, como incumplimientos entenderíamos las obligaciones del protocolo y comunicación con el juzgado, quejas reiteradas de letrados o usuarios, faltar a los principios de la mediación, entre otras. Los sistemas de resolución de reclamaciones están establecidos en los reglamentos de las instituciones de mediación. VALERO LLORCA, J. y COBAS COBIELLA, M.E., «La responsabilidad del mediador a la luz de la Ley 5/2012, de 6 de julio, de mediación en asuntos civiles y mercantiles. Aproximación a la cuestión», Diario La Ley, No 7987, 19 de diciembre de 2012. [Consulta: 20 julio 2017]

19 Anexo 5. Panel de mediadores intrajudiciales de la provincia de... (especificar la provincia correspondiente)

${ }^{20} \mathrm{http}: / /$ www.poderjudicial.es/cgpj/es/Temas/Mediacion/Servicios-de-mediacion/Servicios-que-ofrecenmediacion-Civil/

21 Boletín Oficial de las Cortes Generales de 31 de julio de 2017. Congreso de los diputados XII Legislatura. http://www.congreso.es/portal/page/portal/Congreso/Congreso/Publicaciones/ Punto III del preámbulo del Proyecto de Ley por la que se incorpora la Directiva 2013/11/UE del Parlamento Europeo y del Consejo de 21 de mayo de 2013. [consulta 10 septiembre 2017] 
notificadas por los diferentes Estados miembros de la Unión Europea». Las Instituciones de mediación van a jugar un papel importante en el desarrollo de estas entidades de resolución alternativas de calidad, exigiéndose al Estado garantizar no sólo su existencia, sino que cumplan con los requisitos, garantías y obligaciones exigidas.

\section{II.3. Destinatarios}

Los destinatarios del servicio de mediación intrajudicial serán los justiciables partes de un procedimiento tramitado ante los juzgados de la capital y de los diferentes partidos judiciales de la provincia, que hayan sido derivados por el juez a mediación, a iniciativa del Juzgado o de las propias partes. La mayoría de destinatarios ignoran la mediación, sus representantes pueden influir en la conveniencia de la mediación al caso. Si las oficinas judiciales les facilitan el panel de mediadores lo hace más accesible a elegir el profesional de la zona. Sistema que parece elegido por nuestro ordenamiento con la creación del Registro de Mediadores, y que resulta consecuente con la naturaleza del recurso. Una vez en la mediación, las partes se deben al principio de lealtad, buena fe y respeto mutuo, así como mantener una actitud colaborativa, desde la libertad que implica la voluntariedad (artículo 10 LMACM).

\section{Selección de casos que pueden derivarse a mediación}

Las experiencias pilotos ${ }^{22}$ de mediación intrajudicial en el ámbito del derecho civil previas a la LMACM, se realizaron fundamentalmente en los Juzgados de Familia. El juez mediante providencia decidía que asuntos derivaba a una sesión informativa de mediación, indicando día y hora para realizar dicha sesión, por lo general en sede judicial23. Muchos jueces y magistrados, entendía suficiente como criterio para la derivación en familia, la existencia de menores afectados por el conflicto ${ }^{24}$. Hoy la posible apertura de la mediación intrajudicial a todos los ámbitos materiales del derecho, hace recomendable la elaboración de criterios orientativos para que jueces y magistrado procedan a la derivación, desde el

22 En Huelva la realizamos entre 2009-2012, vinculada a un Master Oficial en Mediación familiar y con menores en la Universidad de Huelva. Acudíamos un día a la semana al juzgado a presenciar las vistas con los alumnos y trasladábamos el análisis de los conflictos que observábamos al aula. Para el Practicum se creó una Unidad de Mediación en la Universidad y se firmó un convenio de colaboración para la realización de mediación intrajudicial entre la Universidad, el Decanato de Jueces y el Colegio de Abogados. A partir de ahí dependía de la voluntad del magistrado de confiar en el recurso de la mediación. Desde aquí el agradecimiento a las Magistradas Dña. Susana Caballero y Dña. María José Cueca Bonilla por el apoyo e impulso que permitieron dar de la mediación en Huelva.

${ }^{23}$ El señalamiento con día y hora de una sesión cada media hora, frustraba a algunos usuarios y a sus letrados que tenía expectativas de iniciar el proceso en la cita prevista. Resulta más operativo y hoy posible que la derivación sea el mediador que recibe el encargo, y este gestione la agenda con la previsión de tiempo por si las partes deciden empezar tras la sesión informativa. La inmediatez es factor importante aquí.

24 Los asuntos derivados eran divorcios, modificaciones de medida, responsabilidades parentales, etc. Y el momento procesal como regla general la derivación se producía en el emplazamiento para la vista, existiendo tiempo suficiente para realizar la mediación. También hubo caso que durante la vista se procede a suspender a a derivar en el mismo acto, casos de ejecución de sentencia. Ver, ORTUÑO MUÑOZ, Pascual «La mediación intrajudicial», en LAUROBA, E., BARRAL, I. y VIOLA, I. (Dirs.) Materiales jurídicos del Libro Blanco de la Mediación en Cataluña, Generalitat de Catalunya, Departament de Justicia, Centre d'Estudis Jurídics i Formació Especialitzada, Barcelona, 2011. 
convencimiento que habrá que estar al caso concreto por la propia complejidad del conflicto y su carácter genuino ${ }^{25}$. En este sentido las Guías del CGPJ incorporan un trabajo recopilatorio que usaremos como base y abordaremos también el asunto sobre la competencia para realizar la selección de casos objeto de derivación.

\section{III.1. Competencia para realizar la selección}

La selección de los casos que pueden derivarse a sesión informativa de mediación la realiza el juez, quien a través de la oportuna resolución invita a las partes y a sus abogados a que acudan a dicha sesión. Dicha derivación implica una valoración ${ }^{26}$ del caso sobre la posibilidad de ser mediado, siendo aconsejable establecer por el órgano judicial unos criterios orientativos para realizar la derivación. Por su parte, el letrado de la administración de justicia informa de la existencia de la mediación en sus resoluciones o puede indicar el punto de información para la mediación habilitado en sede judicial por CCAA a tal fin. Esta labor de informar supone una incluso del recurso en las resoluciones del letrado de la administración de justicia con carácter general, exenta de valoración. Es importante aclarar que la valoración de si el caso es o no mediable le corresponde finalmente al mediador. En cualquier caso resulta altamente recomendable que todos los operadores jurídicos tenga formación en mediación para evaluar la oportunidad del método al caso además de conocer y considerar el trabajo profesional del mediador que emerge en nuestra sociedad.

\section{III.2. Asuntos susceptibles de ser derivados a Mediación en el ámbito Civil y Mercantil}

Centrándonos en el ámbito material del Derecho Privado, podrán ser derivados a mediación aquellos procedimientos civiles cuyo conocimiento sea competencia de los Juzgados de Primera Instancia de los diferentes partidos judiciales de la provincia. Los casos judiciales susceptible de ser derivados a sesión informativa de mediación deben ser seleccionados por el órgano judicial, y éste, no dispone de criterios legales en los que fundamentar dicha acción. En general, el conflicto es complejo, y está sujeto a elementos y

25 CARRETERO MORALES, Emiliano. La mediación civil y mercantil en el sistema de justicia, p. 369-383, Dykinson Madrid, 2016. Completo análisis por materia y recoge la doctrina más autoriza sobre el tema que en general entienden la imposibilidad de hacer una lista de criterios exhaustiva, y sí la conveniencia de establecer criterios orientativos. FAJARDO MARTOS, Paulino, «La posición del abogado en el proceso de mediación», p.2 Disponible en http://www.congresomediacion.es/pdf/PAULINO\%20FAJARDO.pdf, incide en la relevancia de tres criterios que, hacen especialmente indicado el uso de la mediación en conflictos mercantiles. Estos criterios son la existencia de relaciones comerciales continuadas entre las partes, la preservación del riesgo reputacional de las mismas y la presencia de estrategias legales complejas y previsión de dilación en el tiempo. También DI STEFANO, L., "Mediación conectada con los tribunales: estructuración y principios que regulan su funcionamiento", en SOLETO MUÑOZ, H. (Dir.), Mediación y resolución de conflictos. Técnicas y ámbitos. Tecnos, Madrid, 2011, 2a ed., p. 428. MARTíN NÁJERA, T., PÉREZ SALAZAR, M. y UTRERA GUTIERREZ, J.L., «Protocolo para la implantación de la mediación familiar intrajudicial en los juzgados y tribunales que conocen de procesos de familia», Revista de Mediación, Año 2, No 4, octubre 2009, p. 14

26 FREIRE PÉREZ, Rosa, «La posición del Juez ante la mediación: ¿Espectador, participante, garante?», en SOLETO MUÑOZ, Helena. (Dir.), Mediación y resolución de conflictos. Técnicas y ámbitos, Tecnos, Madrid, 2011, p. 281. Y en ALASTRUEY GRACIA, Raquel., «Argumentario sobre la búsqueda de soluciones negociadas en el proceso civil» p.3, disponible en http: www.poderjudicial.es., Interesante su análisis sobre la evaluación, criterios de derivación y formalización de la derivación. MEJÍAS GÓMEZ, J.F., La mediación como forma de tutela judicial efectiva, p. 110, El Derecho, Madrid, 2009. 
circunstancias genuinas, por lo que se recomienda a priori valorar caso a caso. Teniendo en cuenta además que el enfoque de evaluación puede ser eminentemente jurídico. Los expertos en resolución de conflictos ${ }^{27}$ analizan los conflictos desde un prisma más amplio, donde la conversación del Derecho es una parte más. Desde la resolución de conflictos se enseña que el conflicto tiene, como mínimo dos componentes, los sustanciales o materiales y los aspectos relacionales entre sus protagonistas. Cuanto más relevancia, valor o influencia ${ }^{28}$ tenga la relación para las partes en el conflicto, respecto a lo sustancial, más posibilidad de ser mediado, y más utilidad le puede reportar a sus protagonistas.

Además, en todos los conflictos con trascendencia jurídica, subyacen tres conversaciones, una basada en el poder, otra basada en el derecho o la ley, y otra basada en los intereses de las partes ${ }^{29}$. Cuando los asuntos se judicializan las conversaciones basadas en el poder y en el derecho están reflejadas en sus escritos judiciales. La conversación basada en los intereses, puede que no haya existido, o de existir, fuera infructuosa. Puede ocurrir también que basar la resolución del conflicto en la conversación del derecho no beneficie a ninguna de las partes. La casuística es amplia y siempre habrá que estar al caso concreto teniendo presente estos aspectos para una evaluación más completa del asunto. Si el caso se ajusta a estos parámetros, probablemente sea mediable. Las Guías de CGPJ, para facilitar esta labor de análisis y evaluación de casos a derivar a mediación incluye un test en su Anexo III (tipología de casos) ${ }^{30}$ con distintos parámetros y sistema de evaluación

27 ALZATE, Ramón. Análisis y resolución de conflictos. Una perspectiva psicológica. UPV. Bilbao. 1998. LEDERACH, John Paul. Enredos, pleitos y problemas, una guía práctica para resolver conflictos. Editorial Clara Semilla. Colombia. 1985.

${ }^{28}$ Relevancia en el sentido de tener fuerza, peso por la cercanía, parentesco u otros vínculos como, lazos de amistad, de trabajo, vecindad, durabilidad en el tiempo. Cada relación es diferente, y debe tener su marco propio de gestión. Ningún divorcio es igual a otro a nivel relacional y se gestiona de forma similar a nivel sustancial. El factor personal en la gestión de conflictos es clave para la resolución. LEDERACH, John Paul. «Elementos para la resolución de conflictos» En Revista Educación en Derechos Humanos. N. II Noviembre 1990 Uruguay y en Cuadernos de No-violencia, No. 1, México: Ed. SERPAJ, 1989. MOORE, Cristopher. El proceso de Mediación. Métodos y prácticas para la resolución de conflictos. Buenos Aires. Granica. 1993. MULDOON, B. El corazón del conflicto. Barcelona. Paidos. 1998.

${ }^{29}$ URY, Willian, FISHER, Roger, PATTON, Bruce. Obtenga el sí: El arte de negociar sin ceder. Gestión 2000. Barcelona, 2011. MUNDUATE JACA, Lourdes, MEDINA DIAZ, Fco. J. Gestión de conflictos, negociación y mediación. Piramide, Madrid 2006.

\footnotetext{
30 Guía para la práctica de la Mediación intrajudicial del CGPJ, p. 28 a 31. De esta manera, como asuntos donde el aspecto relacional tiene influencia en la resolución del conflicto, conforme al listado de la Guía serian: «a. Cuando las partes mantengan lazos familiares o se perciba una evidente carga emocional, cualquiera que sea la pretensión jurídica formulada. Así como las relaciones entre las partes sean continuadas: sucesiones, particiones hereditarias o división de bienes comunes, reclamaciones entre familiares, alimentos entre parientes, relaciones entre miembros de una pareja, problemas derivados de segundas parejas de ascendientes o descendientes, gestión de empresas familiares, consecuencias patrimoniales de las rupturas de matrimonios o parejas, organismos tutelares y gestión de las tutelas, relaciones de vecindad, inmisiones, medianería, servidumbres, propiedad horizontal, comunidades de bienes, relación entre participes y/o órganos de administración de sociedades, ruptura de relaciones de colaboración empresarial (franquicias, agencia, distribución, etc.), derivadas del contrato de seguro». Y el punto c. «Todos aquellos en que existan entre las partes diversos litigios o se advierta que tras el actual seguirán otros: posibles acciones de repetición, incumplimientos contractuales a consecuencia de acciones dañosas de terceros, reclamaciones frente a empresas insolventes, diversas reclamaciones frente a una misma persona o conjunto de personas». Por otro lado, los asuntos cuya conversación basada en intereses no existió o bien la respuesta que pueda dar el Derecho, no resulta satisfactoria a ninguna de las partes, podríamos agrupar del listado de las Guía de CGPJ los siguiente: «b. Cuando la tutela del derecho suponga necesariamente un coste no reembolsable: reclamaciones de consumidores frente al empresario, reclamaciones de escasa cuantía. d. Cuando el cauce procesal aboque a un resultado de pérdida para ambas partes: ejecuciones hipotecarias, ejecuciones en general, responsabilidad civil por nuevas construcciones
} 
individualizada del caso. Además de ello, la Guía del CGPJ recoge un listado de conflictos judicializados que entienden derivables a sesión informativa de mediación, como mejor posible alternativa que podemos aglutinarlos bajo los dos criterios generales apuntados. Y la doctrina ${ }^{31}$ en el análisis de este asunto coincide en la imposibilidad de crear un listado exhaustivo de casos y en la conveniencia de recopilar criterios orientativos para facilitar al juez su función, hasta una normalizada integración.

\section{Impulso a la mediación: información y derivación a sesión informativa de mediación}

El artículo 17 de la LMACM, bajo el título de «Información y sesiones informativas» identifica dos actuaciones diferentes relacionadas con el impulso y conocimiento de la mediación que también recoge la LEC para los procesos declarativos en sus artículos 414.1 párrafos $2^{\circ}$ y $4^{\text {o } 32}$ y 440.1 párrafo $2^{\underline{0} 33}$ y la disposición adicional segunda de la LMACM para las Administraciones Públicas. Antes de avanzar en el sistema de derivación entendemos necesario clarificar en que consiste una y otra actuación que no son excluyentes, sino complementarias para el impulso de este recurso, de acuerdo con la Directiva 2008/52/CE del Parlamento Europeo y del Consejo, de 21 de mayo de 2008, sobre ciertos aspectos de la mediación en asuntos civiles y mercantiles, por la que los Estados miembros deben alentar a los profesionales del Derecho a informar de las posibilidades que ofrece la mediación ${ }^{34}$.

(LOE). e. Cuando la decisión no permita adaptarse a los matices del caso, a las circunstancias personales o comporte una percepción subjetiva de difícil aprehensión por el Juzgador: imposibilidad de fijar plazos, condiciones, garantías o sustitución de la prestación incumplida, supuestos de insolvencia, derecho al honor, la intimidad o propia imagen. f. Si existe un alto nivel de incertidumbre en el resultado económico pretendido: responsabilidad civil extracontractual, responsabilidad civil médica, responsabilidad civil profesional, en general, reclamaciones por cumplimiento defectuoso, de base técnica, litigios cuya sentencia sea irrecurrible, cuando alguna de las partes lo haya indicado en sus propios escritos de alegaciones.»

31 CARRETERO MORALES, Emiliano. La mediación civil y mercantil en el sistema de justicia, p. 369-383, Dykinson Madrid, 2016. Completo análisis por materia y recoge la doctrina más autoriza sobre el tema, que en general entienden la imposibilidad de hacer una lista de criterios exhaustiva y sí la conveniencia de establecer criterios orientativos. FAJARDO MARTOS, Paulino, «La posición del abogado en el proceso de mediación», p. 2 Disponible en http://www.congresomediacion.es/pdf/PAULIN0\%20FAJARDO.pdf, incide en la relevancia de tres criterios que, hacen especialmente indicado el uso de la mediación en conflictos mercantiles. Estos criterios son la existencia de relaciones comerciales continuadas entre las partes, la preservación del riesgo reputacional de las mismas y la presencia de estrategias legales complejas y previsión de dilación en el tiempo. DI STEFANO, L., "Mediación conectada con los tribunales: estructuración y principios que regulan su funcionamiento", en SOLETO MUÑOZ, H. (Dir.), Mediación y resolución de conflictos..., op. cit., p. 428. MARTÍN NÁJERA, T., PÉREZ SALAZAR, M. y UTRERA GUTIERREZ, J.L., "Protocolo para la implantación de la mediación familiar intrajudicial en los juzgados y tribunales que conocen de procesos de familia", Revista de Mediación, Año 2, No 4, octubre 2009, p. 14

32 Redactados por el apartado diez de la disposición final tercera de la LMACM [Consultado 10 junio 2017]

33 Ley 42/2015, de 5 de octubre, de reforma de la Ley 1/2000, de 7 de enero, de Enjuiciamiento Civil.

34 En consonancia con esta previsión comunitaria, la disposición adicional segunda de la Ley 5/2012, de MACM, vino a establecer que las Administraciones Públicas competentes procurarán incluir la mediación dentro del asesoramiento y orientación gratuitos previos al proceso, previstos en el artículo 6 de la Ley de 1/1996, de 10 de enero, de asistencia jurídica gratuita, en la medida que permita reducir tanto la litigiosidad como sus costes, cumpliéndose con la reforma esta previsión. Así, se incluye expresamente dentro de la prestación relativa al asesoramiento y orientación gratuitos el derecho del beneficiario de la asistencia jurídica gratuita a recibir toda la información relativa a la mediación y otros medios extrajudiciales de solución de conflictos. No obstante, ello no supone que deban asumirse los gastos de la sesión informativa a que se refiere el art 17 de la LMACM. 
Dichas actuaciones tienen objetivos diferentes, pero fines comunes por lo que no son excluyentes sino completarías y necesarias para el impulso de la mediación.

a) La información conforme al artículo 17.2 de la LMACM hace referencia a la posibilidad que tienen las instituciones de mediación de organizar sesiones de información abiertas para las personas que puedan estar interesadas en acudir a este sistema de resolución de conflictos que, «en ningún caso sustituye» a la sesión informativa que el mediador debe realizar a las partes y/o a sus representantes previa al inicio de la mediación conforme al artículo 17.1 de la LMACM. Por otro parte las CCAA parecen asumir la función de proveer de espacios y soportes físicos para propiciar esta labor de informar conforme a la disposición adicional segunda de la LMACM. De esta manera las CCAA, con base en acuerdos con las Consejería de Justicia y el CGPJ ${ }^{35}$ están dando cobertura a esta función informativa a través de los puntos de información a la mediación en el entorno judicial. Los artículos 414.1 párrafos $2^{\circ}$ y 440.1 párrafo $2^{\circ}$ de la LEC, encomiendan esta función de información del recurso de la mediación a los letrados de la administración de justicia. En este sentido se entiende por información la ofrecida a través de trípticos ${ }^{36}$ y folletos, adjuntados a las resoluciones, o facilitados por las oficinas judiciales, incluido el listado del panel de mediadores intrajudiciales en su caso, o indicación del punto de información de mediación intrajudicial habilitado por la CCAA si existiera. Las oficinas judiciales pueden cumplir una importante función de acercar la información si disponen en ellas del material divulgativo al efecto. Así mismo sería recomendable formar a las oficinas judiciales con carácter obligatorio, en el conocimiento del trabajo del mediador y en su posible vinculación con el proceso judicial de manera que puedan facilitar información del recurso de la mediación a los operadores jurídicos y a los interesados. Disponer de la información del panel de mediadores en las oficinas judiciales junto a la información, puede facilitar la ágil designación de mediadores por los letrados y/o las partes.

b) La sesión informativa de mediación ${ }^{37}$, conforme al artículo 17.1 de la LMACM supone el encuentro inicial del mediador designado por la institución de mediación o elegido por las partes y/o sus representantes, que va a realizar la mediación. Esta sesión informativa de mediación tiene por objeto crear entendimiento y confianza sobre el proceso de mediación y sobre cómo el mediador lo va guiar. El mediador puede asegurar la oportunidad del método al caso con una información mínima y determinar también el coste en su caso. Respecto al contenido mínimo de la sesión

35 El CGPJ tiene suscrito convenios de colaboración para el impulso de la mediación con todas las CCAA. Asi mismo dispone de acuerdos con Instituciones Públicas y privadas para el mismo fin. Véase http://www.poderjudicial.es/cgpj/es/Temas/Mediacion/Convenios/Mediacion-civil-y-mercantil/.

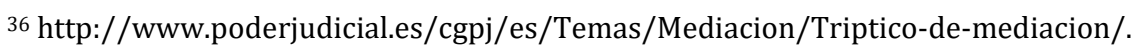

37 MOORE, Cristopher. El proceso de Mediación. Métodos y prácticas para la resolución de conflictos, Granica, Buenos Aires, 1993. MORELLO, L., «Parte la mediazione obbligatoria. Vediamo nel dettaglio come». Disponible en: http://www.diritto24.ilsole24ore.com/civile/civile/primiPlani/2013/09. WISSLER, R.L., "Court-Connected Mediation in General Civil Cases: What We Know from Empirical Research", Ohio State Journal on Dispute Resolution, Vol. 17:3 2002. 
informativa, el mediador debe explicar e informar sobre: su tipo de intervención, los principios de la mediación, mostrarles cómo será la colaboración con los abogados de las partes, los documentos del proceso, la eficacia del posible acuerdo, aproximar una estimación de tiempo, el coste de la mediación y/o los criterios para determinarlo. Esta sesión informativa puede ser o no gratuita, en cualquier caso, las partes deben conocer este aspecto antes de iniciarla ${ }^{38}$. Respecto de algunos principios de la mediación, y tratándose además de sesión informativa intrajudicial, consideramos oportuno hacer algunas puntualizaciones. Cuando el mediador recibe el encargo de realizar la sesión informativa y contacta con las partes y/o sus representantes debe insistir en la voluntariedad ${ }^{39}$ para realizar la mediación, que se extiende a la sesión informativa, cuya información está sujeta al principio de confidencialidad que informa la mediación, salvo "la información de qué parte o partes no asistieron a la sesión no será confidencial” (artículo17. 1 de la LMACM). La sesión informativa intrajudicial tiene lugar cuando el Juez «en atención al objeto del proceso», invita a las «partes a que intenten un acuerdo que ponga fin al proceso, en su caso a través de un procedimiento de mediación, instándolas a que asistan a una sesión informativa» ${ }^{40}$, conforme al párrafo cuarto del número 1 del artículo 414 de la LEC, modificado por la LMACM. Dicha función implica una evaluación por el juez, en atención al objeto del caso, y alude a la sesión informativa del artículo 17.1 de la LMACM. La creación en los partidos judiciales del panel de mediadores e instituciones de mediación intrajudiciales del entorno, permite a las partes decidir

\footnotetext{
${ }^{38}$ La mayoría de las sesiones informativas de mediación intrajudicial se realizan de forma gratuita al objeto de impulsar en conocimiento del recurso. Ello dificulta el reconocimiento profesional del mediador en este escenario, al ampliar para las partes el coste del asunto. El anexo 2 y 3 del panel permite facilitar la información sobre que mediadores e instituciones de mediación que ofrecen esta sesión con carácter gratuito, así como la mediación para los beneficiarios de justicia gratuita.
}

${ }^{39}$ Algunos ordenamientos europeos incorporan como obligatoria y prejudicial esta sesión, como el caso de Italia, y véase respecto a la voluntariedad de esta sesión informativa la Sentencia del Tribunal de Justicia Europeo de 14 de junio de 2017 Tribunal de Justicia de la Unión Europea, Sala Primera, Sentencia de 14 Jun. 2017, C-75/2016, № de Recurso: C-75/2016, Disponible en http://curia.europa.eu/juris/document/document.jsf;jsessionid=9ea7d0f130d577754f5834644e608124fe90 8d8cfbd3.e34KaxiLc3eQc40LaxqMbN4PaN80e0?text=\&docid=191706\&pageIndex=0\&doclang=ES\&mode=req \&dir=\&occ=first\&part=1\&cid=884599, [consulta 10 septiembre 2017] de cuyo texto resulta revelador lo siguiente: «A este respecto, si bien el artículo 1, primera frase, de la Directiva 2013/11 utiliza la expresión "si así lo desean", cabe señalar que la segunda frase de este artículo establece explícitamente la posibilidad de que los Estados miembros establezcan la obligatoriedad de la participación en los procedimientos de resolución alternativa, siempre que su legislación no impida a las partes ejercer su derecho de acceso al sistema judicial. [...] En efecto, este procedimiento puede ser iniciado por las partes, sugerido u ordenado por un órgano jurisdiccional o prescrito por el Derecho de un Estado miembro. Asimismo, con arreglo al artículo 5, apartado 2, de la Directiva 2008/52, ésta no afectará a la legislación nacional que estipule la obligatoriedad de la mediación, siempre que tal legislación no impida a las partes el ejercicio de su derecho de acceso al sistema judicial. Como resulta del considerando 13 de la Directiva 2008/52, el carácter voluntario de la mediación reside, por tanto, no en la libertad de las partes de recurrir o no a este proceso, sino en el hecho de que "las partes se responsabilizan de él y pueden organizarlo como lo deseen y darlo por terminado en cualquier momento". Así pues, lo que tiene importancia no es el carácter obligatorio o facultativo del sistema de mediación, sino que se preserve el derecho de las partes de acceder al sistema judicial. Con este fin, como señaló el Abogado General en el punto 75 de sus conclusiones, los Estados miembros conservan su plena autonomía legislativa, a condición de que se respete el efecto útil de la Directiva 2013/11».

40 Párrafo cuarto del número 1 del artículo 414 introducido en su actual redacción por el apartado diez de la disposición final tercera de la LMACM. 
a quién designan, o en su caso, al Juez derivar a una institución de mediación que designa al mediador de forma ágil, lo que optimiza los recursos y favorece la posibilidad real de la mediación, al permitir gestionar el tiempo de forma rápida y directa entre el mediador y las partes o sus representantes tanto para la sesión informativa como para la mediación. Nada impide que, tras la celebración de la sesión informativa, las partes decidan comenzar la mediación y procedan a la firma del acta de constitución del proceso de mediación. También puede dejarse unos días de reflexión para decidir si inician no a la mediación. El mediador debe acudir a la sesión informativa con esa previsión del tiempo, ya que la inmediatez, es un factor clave en la oportunidad de iniciar la mediación ${ }^{41}$.

Es importante la participación de las partes o sus representantes desde el inicio en la designación del mediador. Forma parte de la esencia natural del método auto compositivo de soluciones. Si las partes o sus representantes no cuentan previamente con la información de los posibles mediadores, o se designa a través de un turno existente en la institución de mediación, o por designación del Juez, puede ocurrir que exista alguna causa concurrente (amistad, vecindad, profesión, formación, experiencia, enemistad etc.) entre el mediador y las partes o sus representantes, que pudiese cuestionar su imparcialidad. En ese caso, el mediador debe comunicarla de forma clara a todos los asistentes, en virtud del principio de transparencia del proceso. Además, debe facilitar el cauce para que la institución de mediación designe a otra persona mediadora para llevar a efecto la sesión informativa de mediación. Cosa que resulta más difícil que ocurra si se opta por la designación de las partes, se les facilita un panel de mediadores, para que ellas o sus representantes elijan.

Aclarada la diferenciación la acción de informar y la derivación a sesión informativa de mediación, avanzamos describiendo cómo entendemos que podría ser eficaz el sistema de derivación intrajudicial a sesión informativa, pues la acción de informar puede quedar reducida a la inclusión de un párrafo en las resoluciones del letrado de la administración de justicia, a la entrega de información escrita desde la oficina judicial o desde los puntos de información de las CCAA tengan habilitado para ello en sede judicial.

\section{IV.1. Resolución del Juzgado}

El juez, mediante una resolución motivada, acuerda la derivación del caso a sesión informativa a la institución/entidad/colegio profesional/mediador que soliciten las partes de mutuo acuerdo (adjuntado el panel de mediadores) o, en su caso, el juez deriva a una institución de mediación, la que procede a la designación del mediador conforme a sus criterios reglamentariamente establecido. También puede derivar a la información a los puntos habilitados por la CCAA o institución de mediación que lo dispusiera. En esa

\footnotetext{
${ }^{41}$ En las experiencias pilotos previas a la LMACM, la providencia incorporaba el señalamiento de día y hora en sede judicial para la sesión. Ello restringía las posibilidades de la mediación pues prácticamente no se podía realizar en ese momento, se aplazaba y luego venían o no, en otros casos deseaban comenzar pero era materialmente imposible. La casuística es amplia. Sin embargo favorece la posibilidad de la mediación que el mediador pueda crear la agenda de acuerdo con las partes y sus representantes con la previsión de poder iniciar la mediación. Hoy con el Registro del Ministerio el Juez puede directamente indicar a las partes la designación del mediador a los allí inscritos.
} 
resolución se explica de forma sucinta en qué consiste la mediación, recordando que la información de qué parte asiste no es confidencial, pudiendo después el órgano judicial valorar $^{42}$ esa circunstancia junto con el resto del material probatorio. Es aconsejable informar de que, en caso de no desear asistir, las partes deberán explicar los motivos de su decisión de conformidad con lo dispuesto en el apartado 1ํ del segundo párrafo del artículo 414 de la LEC. No será precisa la suspensión del proceso salvo que lo soliciten ambas partes, y en su caso, se acordará por el plazo previsto en el artículo 19 de la LEC. Se tendrá en cuenta que, si se efectúa la derivación a mediación sin suspensión del curso de los autos, exista plazo suficiente para practicar las sesiones de mediación entre la citación y la celebración de la vista correspondiente ${ }^{43}$.

El juez en atención al objeto del proceso y haciendo uso del panel de mediadores intrajudiciales, remite su resolución a la institución de mediación al objeto de celebrar la sesión informativa. Las Guías del CGPJ en su DOC. 12 nos facilita una ficha de derivación para que los mediadores dispongan de los datos necesarios: órgano judicial que deriva, tipo de proceso y número, cuestiones sobre las que versa el litigio, momento procesal en el que está la causa, en su caso, fecha del siguiente señalamiento o acto, y datos personales y de contacto de los litigantes, sus abogados y procuradores. A dicha ficha de derivación le incorporamos, en el reverso, un cuadro informativo sobre el resultado de la sesión informativa ${ }^{44}$. De esta manera, el mismo documento será devuelto por correo electrónico al Juzgado que realizó la derivación, por la institución o por el mediador, tras la realización de la sesión.

La mediación se prestará, bien a través de un solo mediador o a través de la comediación, con la intervención de más de un mediador, a criterio de la institución/entidad/colegio profesional/mediador a la que se haya derivado el asunto atendiendo a las características, complejidad y circunstancias del mismo, de lo que se informará en todo caso a las partes en la sesión informativa.

IV.2. Momento de la derivación

Siguiendo fielmente las directrices de la guía del CGPJ ${ }^{45}$, las fases procesales para la derivación son las siguientes:

42 BROOKE, H., "Mediation in the UK today", disponible en http://www.cedr.com.sepen Inglaterra existe el criterio de condenar en costas cuando injustificada no asisten y han sido derivado judicialmente. Resulta interesante a estos efectos el caso recogido en CARRETERO MORALES, Emiliano. La mediación civil y mercantil en el sistema de justicia, p. 385, Dykinson Madrid, 2016.

43 ZAPATERO GÓMEZ, J., SÁEZ VALCÁRCEL, R. y ORTUÑO MUÑOZ, P. “Conclusiones”, en SÁEZ VALCÁRCEL, R. y ORTUÑO MUÑOZ, P. (Dirs.), Alternativas a la judicialización de los conflictos: la mediación, Consejo General del Poder Judicial, Centro de Documentación Judicial, Madrid, 2007.

44 Anexo 4 Ficha de derivación e información del resultado de sesión informativa. esto último ha sido incorporado al modelo de la Guía del CGPJ, por la conveniencia de su utilización en la experiencia piloto de mediación intrajudicial realizada en Huelva en el juzgado num.7 entre los años 2009 a 2012.

45 Guía del CGPJ p.18. BONET NAVARRO, A. (Dir.), Proceso civil y mediación. Su análisis en la Ley 5/2012, de mediación en asuntos civiles y mercantiles, Thomson Reuters Aranzadi, Pamplona, 2013 iscepi-WISSLER, R.L., "CourtConnected Mediation in General Civil Cases: What We Know from Empirical Research", Ohio State Journal on Dispute Resolution, Vol. 17:3 2002. 
«En el decreto de admisión a trámite de la demanda el letrado de la administración de justicia incorporará un párrafo informando de la posibilidad de acudir a mediación sin suspender el proceso. (Alternativas DOC.2 y DOC.4)»46. Asimismo al dar traslado de la demanda «adjuntará una hoja informativas sobre los centros de mediación a que puede dirigirse (DOC.3 y 3 bis)». Dicha hoja informativa puede ser el tríptico del CGPJ acompañado del panel de mediadores intrajudiciales que proponemos, ordenados por partido judicial y jurisdicción a nivel provincial. Además resulta conveniente que en el juzgado, se tenga a disposición de las partes o de sus representantes que así lo soliciten información sobre dicho panel para la selección del mediador o en su caso de la institución de mediación a los que pueden dirigirse. Una posibilidad es incorporarlo «en común»47, indicando a los funcionarios que pueden proceder a facilitar dicha información a quien lo solicite, para lo cual se formará debidamente a los funcionarios. Para ello el panel de mediadores intrajudiciales debe esta pertinentemente configurado y reflejado en el Anexo 5.

En los procesos declarativos con contestación escrita (entre los que se incluye actualmente el juicio verbal, tras la reforma operada en el art. 438.1 LEC por Ley 42/2015) la derivación podrá hacerse una vez estén ambas partes personadas en el procedimiento y en cualquiera de los siguientes momentos procesales:

- Durante el periodo que va desde que las partes han sido emplazadas hasta la fecha de la audiencia previa o de la vista del juicio verbal, si es que ésta se acuerda (art. 438.4 y 440 LEC). En la resolución convocando a la audiencia previa o a la vista del juicio verbal se incluirá el párrafo correspondiente (DOC. 5) ${ }^{48}$.

- En la diligencia de ordenación convocando a las partes a la audiencia previa, el letrado de la administración de justicia incorporará un párrafo convocando personalmente a los litigantes (Doc.5). De acordarse la derivación se documentará por escrito mediante diligencia de constancia (DOC.6) ${ }^{49}$.

Hasta este momento procesal entendemos que, de iniciarse una mediación, seria por la voluntad de las propias partes o por el asesoramiento de sus letrados tras la información recibida del letrado de la administración de justicia.

En el acto de la Audiencia Previa, de no haberse acordado la derivación con anterioridad, el juez o magistrado en ese acto informará personalmente a las partes y, en su caso, las convocará a una sesión informativa sobre mediación.

\footnotetext{
46 Guía del CGPJ p.34 y 36.

${ }^{47}$ En común alude al término de comunicación del Juez con su oficina judicial a través del sistema de gestión informática procesal de cada Juzgado. El Juez en el sistema interno de comunicación con su oficina puede crear una carpeta de mediación en dentro de la carpeta común que incorpore los anexos, documentos de la Guía y Tríptico informativo del CGPJ, así como el panel de mediadores Anexo 5. La oficina judicial tiene acceso y a demanda de cualquier letrado, procurador o particular puede facilitar la información si previamente se informa a los miembros de la oficina judicial.

48 Guía del CGPJ p.37.

${ }^{49}$ Guía del CGPJ p.37.
} 
- $\quad$ En la parte dispositiva de las resoluciones judiciales definitivas que se dicten (autos o sentencias), a la vista de las circunstancias del litigio el juez o magistrado podrá incluir un párrafo en que se ofrezca a las partes la posibilidad de acudir a mediación para resolver cualquier discrepancia que subsista entre ellas en relación con lo resuelto, su interpretación o ejecución, convocándolas, si el caso lo aconseja, a una sesión informativa sobre mediación.

En los procesos especiales, concretamente en familia, donde la mediación intrajudicial es un recurso eficaz complementario para la gestión y resolución del conflicto, los protocolos de actuación, respecto a las fases procesales de derivación, «lo primero que es necesario señalar es que no se puede dar instrucciones detalladas y que dependerá de las circunstancias de la unidad familiar y de la urgencia del caso»50. La LEC deja libertad al órgano judicial y cada familia y organización del servicio de mediación es diferente por ello la derivación deberá acomodarse a cada supuesto. En cualquier caso, ello nos permite insistir en el valor añadido de configurar un panel de mediadores familiares intrajudiciales que en cada partido judicial se inscriba, especificando su pertenencia o no a registros autonómicos de mediadores familiares, su experiencia y el carácter gratuito o no de su servicio. Disponer en los Juzgados de Familia de dicha información ordenada conforme a los anexos del panel que proponemos, facilita la actuación inmediata del Juez en atención al caso, la urgencia y la libertad del órgano judicial. A partir de ahí el protocolo de mediación familiar intrajudicial establece los distintos momentos procesales en los que el Juez puede proceder a la derivación a sesión informativa intrajudicial. La preferencia seria en el señalamiento para la vista y aprovechar los tiempos hasta su celebración ${ }^{51}$, también es posible en la fase de medidas provisionales y en función de la urgencia en adoptar medidas, o bien finalizada la comparecencia, en el propio auto resolutorio. Igualmente cuando se admita prueba y se interrumpa la vista para practicarla, y en la sentencia definitiva en aras de mejorar la comunicación entre los padres para tratar cuestiones de sus hijos y resulte preventiva para el futuro. Cabe la derivación en ejecución de sentencia a la vista de la oposición de la ejecución, así como en segunda instancia ${ }^{52}$.

En los procesos de ejecución una vez se ha dado traslado del despacho de ejecución al ejecutado, aunque no se haya personado en el procedimiento. En todo caso, el letrado de la administración de justicia intentará derivar a mediación todas las ejecuciones de hacer, cuando exista conflicto sobre el cumplimiento exacto de lo ordenado en sentencia. (Doc. 7). La convocatoria en el caso de ejecuciones hipotecarias es recomendable que se realice por el Letrado de la Administración de Justicia al solicitar la certificación de cargas y con

50 Protocolo de mediación familiar de la guía del CGPJ p. 57

${ }^{51}$ Como indica el Protocolo de la Guía del CGPJ p. 58, nada impide que se realice en el momento de admisión a trámite de la demanda así como adjuntar información en el emplazamiento al demandado y en las citaciones a comparecencia en las medidas provisionales coetáneas.

52 Interesante el planteamiento del protocolo de las ventajas que, en la segunda instancia, Guía del CGPJ. P.59 y en CARRETERO MORALES, Emiliano. La mediación civil y mercantil en el sistema de justicia, p 383-389, Dykinson Madrid, 2016. 
anterioridad a la convocatoria de la subasta. (Doc. 8) ${ }^{53}$ En los procesos concursales, en el trámite de anuncio de situación pre-concursal previsto en el artículo 5 bis de la Ley, en la medida de que, en función de las circunstancias, pueda preverse un beneficio tanto para el deudor como para los acreedores» ${ }^{54}$.

\section{IV.3. Sistema de derivación}

La derivación por parte del juzgado puede ser a recibir información sobre la mediación, nada lo impide; o bien a realizar de la sesión informativa conforme al artículo 17. de la LMACM.

a) Si la derivación a es informar, hay que conocer el sistema de gestión organizado desde la CCAA correspondiente o las instituciones de mediación que presten dicha función ${ }^{55}$. Ninguno de los convenios concertados entre el CGPJ y las CCAA, así como con colectivos profesionales (abogados, procuradores, etc.) establece exclusividades e incompatibilidades para ello. Muy al contrario, subyace en ellos la filosofía de apertura para la divulgación y desarrollo de la mediación. Algunas CCAA a través de sus Consejerías de Justicia, conforme a la disposición adicional segunda de la LMACM están habilitando espacios para informar sobre la mediación en sede judicial. Sin embargo, los partidos judiciales que no disponen de dichos puntos, el panel de mediadores intrajudiciales resulta útil al disponer de la información de que mediador o institución de mediación ofrece esa información de mediación. El propio juzgado puede facilitar estos listados. Sería aconsejable su incorporación y actualización a través de la web del CGPJ.

La resolución puede incorporarse en «común» para que todos los funcionarios tengan acceso a la misma. La resolución se notificará a las partes personalmente si no están personadas en el procedimiento a través de procurador y en caso contrario a través de su representación procesal. También se envía al punto de información un correo electrónico adjuntando la correspondiente ficha de derivación (Anexo 4) con los datos ya indicados de procedimiento (órgano que remite, partes, letrados, procuradores, asunto, etc.). Posteriormente el punto de información o la institución remitirá por el mismo conducto, al Juzgado que haya realizado la derivación, de vuelta la ficha comunicando el resultado de la reunión, si las partes han acudido y si han aceptado o no iniciar un proceso de mediación. En dicha reunión se les facilitaría el listado o panel de mediadores e instituciones de mediación intrajudiciales e información para facilitar la selección del mediador.

\footnotetext{
53 Guía del CGPJ p.37

54 Guía del CGPJ p.18

55 BROOKE, H., "Mediation in the UK today", disponible en http://www.cedr.com. BUTTS GRIGGS, Thelma, "La mediación en los Estados Unidos: contexto y experiencias", en Cuadernos de Derecho Judicial, Consejo General del Poder Judicial, 2005. WISSLER, R.L., "Court-Connected Mediation in General Civil Cases: What We Know from Empirical Research", Ohio State Journal on Dispute Resolution, Vol. 17:3 2002.
} 
b) Si la derivación es a sesión informativa de mediación, previa al proceso, el juez dispone del panel de mediadores intrajudicial (Anexo 5), y en atención a su propio criterio $^{56}$ tendría varias opciones: podría remitir a las partes la información del panel para promover la auto designación o remitirles al Registro de Mediadores del Ministerio de Justicia; podría designar a una Institución de mediación en atención a las circunstancias del caso, (institución/asociación/colegio profesional/mediador) que el juez designe de entre los incluidos en el panel de mediadores intrajudiciales. En este sentido, ha sido tradicionalmente polémica la forma de designación de profesionales por parte del juez (peritos, administradores concursales, por ejemplo). La LMACM parece resolver el asunto respecto a la figura del mediador en el artículo 5 de la LMACM con la previsión de las instituciones de mediación y sus exigencias legales. Así, el Juez puede derivar en «atención al objeto» y conforme a su criterio, a la institución de mediación que estime oportuna, y no necesariamente tiene que designar a la persona física mediadora que la lleve a efecto. Si deriva a una institución de mediación constituidas según el artículo 5 LMACM e incluida en el panel de mediadores intrajudiciales, será ésta la que designe al mediador para realizar la sesión informativa, conforme a los criterios de designación que tengan reglamentariamente establecido. De esta manera, la responsabilidad en la designación del mediador recae en la propia institución, salvo que por las partes se proceda a seleccionar el mediador del panel intrajudicial, criterio que debiera ser preferente acorde con la naturaleza del método.

Del mismo modo, los letrados, pueden si lo estiman conveniente, especificar en sus demandas, la institución que resulte de su preferencia a efecto de una posible derivación judicial a sesión informativa. Nada impide que el letrado de un pleito considere la oportunidad de la mediación y pueda especificar en su escrito alguna referencia de derivación a Institución de mediación o a mediador. Lo que sí es recomendable que estos, en la mediación intrajudicial, estén inscritos en el Registro de Mediadores del Ministerio de Justicia.

La resolución del juez puede incorporarse en «común» para que todos los funcionarios tengan acceso a la misma. Y también se notifica a las partes personalmente si no están personadas en el procedimiento a través de procurador y en caso contrario a través de su representación procesal. Y se envía a la institución/entidad/colegio profesional/mediador un correo electrónico adjuntando la correspondiente ficha de derivación (Anexo 4) con los datos ya

56 Una vez que el juez valora la posibilidad de derivar a mediación, cómo selecciona al mediador. Consideramos probable que los criterios del Juez estarán vinculados al asunto y a la especialización, preparación, disponibilidad o cualquier otro que pueda considerar apropiado. Así imaginamos que un conflicto de materia concursal es más probable que se derive a la Institución de mediación del Colegio de Abogados o el Colegios de Economista, frente a otros colectivos. Nada impide que lo realice por turnos conforme a la lista del panel o por insaculación como los peritos, etc. MARTÍN DIZ, F., La mediación: sistema complementario de administración de justicia, CGPJ, Madrid, 2010. ALZATE, Ramón. Análisis y resolución de conflictos. Una perspectiva psicológica. UPV. Bilbao. 1998, recoge la tradicional diferencia de la mediación contractual y la mediación emergente que sustenta el conocimiento del mediador del contexto de actuación y con ello la especialidad del mismo. Así han proliferado en los EEUU mediadores en herencia, familia, comercial, etc. 
indicados de procedimiento (órgano que remite, partes, letrados, procuradores, asunto). Una vez que disponen de la información, y conforme hemos previsto en el protocolo de actuación, «Es aconsejable que por los mediadores se realice una llamada de teléfono a los interesados para confirmar la cita y comenzar a hablar sobre la mediación. Los mediadores con la información de las partes y en los cinco días siguientes a recibir la derivación y aceptarla, deberá promover la realización de la misma. Realizada la sesión y si todas las partes y el mediador deciden abrir el proceso podrán hacerlo. Y en su caso debe dejar un espacio de al menos tres días para la reflexión y confirmar la voluntad de realizar el proceso. Posteriormente el mediador remitirá por el mismo conducto, al Juzgado que haya realizado la derivación, de vuelta la ficha comunicando el resultado de la reunión, si las partes han acudido, si han aceptado o no el proceso de mediación» ${ }^{57}$.

c) Especialidad en asuntos de familia en el que los litigantes gocen del beneficio de Justicia Gratuita de la Ley 1/1996 de 10 de Enero. En estos supuestos el Juzgado de Familia podrá derivar asuntos para realizar sesión informativa, además de al panel de mediadores, que contiene la información de que Instituciones atienden incluso programas de gratuidad, al Registro de mediadores familiares existentes en las CCAA $^{58}$. Recuérdese que el Anteproyecto de Ley de Impulso a la Mediación introduce la mediación como prestación en el derecho a la asistencia jurídica gratuita.

\section{Coste de la mediación intrajudicial}

El artículo 15 de la LMACM establece que «el coste de la mediación, haya concluido con acuerdo o no, se dividirá por partes iguales entre las partes, salvo pacto en contrario». Por lo tanto, no será gratuita. Sobre las sesiones informativas de mediación, ningún texto normativo exige su gratuidad. Sin embargo, la práctica comúnmente aceptada en casos intrajudiciales ha sido su realización gratuita. En sede extrajudicial las instituciones prevén el pago de una tasa a la solicitud del servicio de mediación pues conlleva la apertura de un expediente y gestión de protocolos de actuación ${ }^{59}$. La práctica de la mediación intrajudicial

57 El protocolo para la derivación intrajudicial a mediación que elaboramos, ha sido aprobado por la Junta de Jueces de Huelva, y por el TSJA, y se encuentra en trámite de inscripción en el Registro de Propiedad intelectual del Andalucía, y podemos hacer llegar a cualquier interesado. Los plazos referenciados son para la ciudad de Huelva, habrá que evaluar las dinámicas de cada lugar y el tiempo de tramitación de los expedientes.

58 Los reglamentos autonómicos de las leyes de mediación familiar autonómicas deben ser adaptados al marco nacional en cuanto a las exigencias formativas de los mediadores. Por ello, los Registros Autonómicos de Mediadores Familiares deben permitir el acceso a sus listados a los mediadores que cumplan las exigencias de las formativas conforme a la LMACM.

http://www.juntadeandalucia.es/organismos/igualdadypoliticassociales/areas/infanciafamilias/mediacion-familiar.html

${ }^{59}$ La solicitud del servicio a la institución activa la labor de coordinación, designación del mediador, emisión de un acta de asistencia como mínimo, respuesta al juzgado del resultado. Esta más que justificada la existencia de dicha tasa aunque produzca rechazo pues no olvidemos que el ciudadano esta incurso ya en un proceso judicial con el coste que ello conlleva. Ver webs de CEDR, SIGNUM, Colegios Profesionales. BARONA VILAR, Silvia, Mediación en asuntos civiles y mercantiles en España, Tirant lo Blanch, Valencia, 2013. SOLETO MUÑOZ, Helena, 
en nuestro país ha estado asociada a la gratuidad del recurso para el ciudadano, bien porque existían programas subvencionados de las CCAA o municipales, sobre todo en programas de familia, o bien por el trabajo altruista de los mediadores tratando de difundir el recurso a la ciudadanía. De manera que está comúnmente aceptado que la sesión informativa sea gratuita.

Igualmente se prestará el servicio de mediación de forma gratuita, asumiendo el coste la institución/entidad/colegio profesional/mediadora a quien se haya derivado el asunto, para las partes que sean titulares del derecho de asistencia jurídica gratuita, y que hubieran adquirido este compromiso en el Anexo 2, al ser incluidas en el panel de mediadores. Todo ello sin perjuicio de la futura inclusión del servicio de mediación intrajudicial en el contenido material del derecho a la asistencia jurídica gratuita y de las subvenciones o financiación conforme al compromiso asumido por la CCAA 60 .

En cualquier caso, volvemos a recordar la previsión legal del Anteproyecto de Ley de Impulso a la Mediación, que introduce la mediación como prestación en el derecho a la asistencia jurídica gratuita, modificando el art 6 de la Ley 1/1996 d 10 de enero, de asistencia jurídica gratuita.

Para los justiciables no titulares del derecho a la asistencia jurídica gratuita, el coste de las sesiones de mediación será el que se fije por la institución/entidad/colegio profesional/mediador, debiendo las partes tener conocimiento del mismo con anterioridad a prestar el consentimiento informado. El mediador tiene la obligación de especificar el coste de la mediación durante la sesión informativa, o en su caso el procedimiento específico para definir el coste en cada caso, ya sea por horas o por una cuantía concreta. Y prever en atención al caso, otros posibles costes (tasaciones, informes, evaluaciones, etc.).

\section{Desarrollo de la mediación intrajudicial}

\section{VI.1. Sesión informativa}

A la sesión informativa convocada por el juez, deben acudir en todo caso las partes, pudiendo ir acompañadas de sus abogados. En mediación intrajudicial es muy habitual y conveniente la presencia de aquellos, pues muchos conocen allí cuál es su función en la mediación ${ }^{61}$. En dicha sesión se informará a las partes de las características del proceso de mediación, ventajas, los principios informadores, voluntariedad, confidencialidad, imparcialidad, neutralidad, desarrollo de las sesiones de la mediación, costes, duración, como se incorpora el resultado al proceso en curso, y demás aspectos que se estimen

\footnotetext{
"La mediación conectada con los tribunales", en SOLETO MUÑOZ Helena. (Dir.), Mediación y resolución de conflictos. Técnicas y ámbitos, 2a ed., Tecnos, Madrid, 2013.

60 En Andalucía, a través de la Consejería de Justicia e Interior, la cláusula tercera, apartado b) del Convenio de Colaboración para la promoción de la Mediación, entre dicho organismo y el CGPJ celebrado en Madrid el 29 de Julio de 2015. BARONA VILAR, Silvia, Mediación en asuntos civiles y mercantiles en España, Tirant lo Blanch, Valencia, 2013. BONET NAVARRO, A. (Dir.), Proceso civil y mediación. Su análisis en la Ley 5/2012, de mediación en asuntos civiles y mercantiles, Thomson Reuters Aranzadi, Pamplona, 2013.

61 ORTUÑO MUÑOZ, Pascual, «El papel del abogado en la mediación», Abogados, octubre 2009.
} 
pertinentes por los mediadores como la función en la mediación de los asesores con independencia de su concurrencia al acto o no.

Las partes, al final de la sesión informativa o en el plazo de cinco días, deberán comunicar a los mediadores su decisión sobre iniciar o no el proceso de mediación, debiendo documentarse por escrito y con firma de los interesados la asistencia o no a la sesión informativa y, en su caso, la aceptación de iniciar el proceso de mediación. Los abogados pueden o no asistir, en función de los asuntos, y en caso de no asistir el mediador establecerá un sistema de comunicación con ellos, al ser los responsables de informar los pactos y dar forma jurídica al acuerdo ${ }^{62}$.

Respecto al lugar de celebración, en atención al caso, y al número de personas concurrentes, tendrá el mediador que prever dicha circunstancia y desde el parámetro de la neutralidad podrá realizarla en la institución de mediación, si dispone de espacio, en su despacho, o donde llegue a un entendimiento con las partes y suponga un espacio neutral, o aceptado por todos como tal.

\section{VI.2. Información al Juzgado}

Una vez celebrada la sesión informativa, con o sin asistencia de una o de todas las partes, o transcurrido el plazo concedido a las partes para decidir sobre la aceptación de iniciar el proceso de mediación, la institución/entidad/colegio profesional/mediador comunicará al jugado correspondiente en el plazo de tres días el resultado de la misma, la asistencia o inasistencia de cada una de las partes y, en su caso, la aceptación a iniciar el proceso de mediación mediante la devolución al Juzgado de la ficha de derivación correspondiente a cada asunto.

\section{VI.3. Sesiones de mediación}

La mediación comenzará mediante una sesión constitutiva con los requisitos previstos en el artículo 19 de la LMACM, pudiendo desarrollarse en una o más sesiones, si bien la duración del procedimiento de mediación será lo más breve posible y sus actuaciones se concentrarán en el mínimo número de sesiones conforme al artículo 20 de la LMACM. Respecto al lugar de celebración hacemos extensivo para las sesiones de mediación lo comentado para la sesión informativa. En todo caso podrán las partes interesar la suspensión del procedimiento de conformidad con lo previsto en el artículo 19 de la LEC. Si bien como hemos comentado según el momento procesal en el que se produce la derivación no resulta necesario por el aprovechamiento de los tiempos muertos en la dilación del proceso. Resulta redundante, pero recordamos que no sólo los mediadores intrajudiciales deben ajustarse a las exigencias de la LMACM, además de exigirles la inscripción en el registro, también el proceso de mediación debe ajustarse a los preceptos de la LMACM y desarrollarse conforme a ella.

62 CORDÓN MORENO, F. y SÁNCHEZ POS, M.V., La Ley de Medidas de Agilización Procesaly la Ley de Mediación: Exposición de las reformas recientes de la Justicia Civil, Thomson Reuters Aranzadi, Navarra, 2012. FAJARDO MARTOS, Paulino, «La posición del abogado en el proceso de mediación». Disponible en: http://www.congresomediacion.es/pdf/PAULINO\%20FAJARDO.pdf DI STEFANO, "Mediación conectada con los tribunales: estructuración y principios que regulan su funcionamiento", en SOLETO MUÑOZ, H. (Dir.), Mediación y resolución de conflictos. Técnicas y ámbitos, Tecnos, Madrid, 2011. 


\section{Incorporación del resultado al procedimiento judicial}

«En el caso de finalizar la mediación sin acuerdo, se comunicará al órgano judicial. Dicha comunicación dará lugar a la continuación de los trámites tal como estuvieran previstos (si no se ha suspendido), o a su reanudación (si previamente se había acordado la suspensión)», siempre que así lo interesen las partes. Si la mediación finaliza con acuerdo, éste puede ser incorporado al proceso judicial conforme al poder dispositivo de las partes. Por lo tanto deben ser las partes las que soliciten al juez, con las consecuencias procesales correspondientes, a) el desistimiento bilateral; b) la renuncia a la acción; c) la desaparición sobrevenida del objeto del proceso; d) la homologación judicial del acuerdo63. Las partes también pueden decidir poner fin al litigio y optar por elevar a escritura pública notarial el acuerdo de mediación ${ }^{64}$.

El mediador debe recabar de las partes y sus abogados su voluntad al respecto, incluso resulta recomendable dejar reflejado en el acuerdo de mediación, como un pacto más, como van a proceder al cierre del proceso judicial y sus costes. Y deben ser las partes quienes comuniquen su opción y la forma en que desean documentar públicamente el acuerdo. Si tras recibir la comunicación de terminación de la mediación con acuerdo, las partes no indicaran nada al tribunal en un plazo prudencial, se les requerirá a las partes para que lo aporten o manifiesten su voluntad respecto al pleito.

«La homologación del acuerdo deberá efectuarse siempre que así solicite, que esté justificada la capacidad de las partes que lo acuerdan y salvo que afecte a derechos indisponibles (DOC. 11 Guía CGPJ)» ${ }^{65}$. El acuerdo alcanzado puede exceder subjetiva u objetivamente del planteamiento inicial del juicio, ya que la flexibilidad de la mediación lo permite. Las partes pueden tratar en mediación las controversias que estimen conveniente e incorporar diferentes obligaciones de las propias partes o de terceros. Y el acuerdo de mediación afectará a diversos juicios, «se homologará por el Juez que hubiere efectuado la derivación y se indicará a las partes la obligatoriedad de incorporarlo a los demás procesos o bien de desistir de los mismos, pues únicamente el acuerdo homologado surtirá efectos será ejecutable- en el procedimiento en cuanto al objeto y sujetos del procedimiento en el que se acordó la derivación a mediación» ${ }^{66}$.

63 GONZÁLEZ MARTÍN, L. A., «Aspectos procesales de la Ley de Mediación», Iuris, Actualidad y Práctica del Derecho, 183, enero 2013. BARONA VILAR, Silvia, Mediación en asuntos civiles y mercantiles en España, Tirant lo Blanch, Valencia, 2013. CARRETERO MORALES, Emiliano. La mediación civil y mercantil en el sistema de justicia, p. 383-389, Dykinson Madrid, 2016. CORDÓN MORENO, F. y SÁNCHEZ POS, M.V., La Ley de Medidas de Agilización Procesal y la Ley de Mediación: Exposición de las reformas recientes de la Justicia Civil, Thomson Reuters Aranzadi, Navarra, 2012.

64 Si el acuerdo de mediación incorpora pactos que exceden considerablemente de la cuestión objeto del proceso, y no son asuntos de otros litigios, el Juez quizás solo homologaría la cuestión pedida. Y ante una homologación parcial quizás las partes opten por la elevación a público del acuerdo.

\footnotetext{
${ }^{65}$ Guía del CGPJ p.41

${ }^{66 G u i ́ a ~ d e l ~ C G P J ~ p .20 ~}$
} 


\section{Sistema de evaluación y control}

La Guía del CGPJ ${ }^{67}$ prevé, para el seguimiento de la implantación de la mediación en los Juzgados civiles y mercantiles, dos tipos de controles:

\section{a) Control interno}

Al objeto de controlar por los juzgados los procesos derivados y evaluar su implantación y eficacia, resulta conveniente que cada juzgado elabore un registro particular incorporado al sistema informático judicial correspondiente, o en otro caso realizarse mediante página Excel en la que se anoten los datos del Doc. 12 de la Guía del CGPJ68. Para facilitar esta labor, es por lo que se ha introducido, en el reverso de la Ficha de Derivación a mediación (Anexo 4), la información del devenir de la sesión informativa y, en su caso, la del proceso de mediación (Reverso del Anexo 4) ${ }^{69}$.

\section{b) Control por el CGPJ}

Las instituciones de mediación deben remitir semestralmente al CGPJ, por correo electrónico las fichas con los datos de los resultados de las mediaciones debidamente cumplimentadas ${ }^{70}$. Además, las instituciones de mediación, o el mediador en su caso, deben realizar una encuesta de satisfacción ${ }^{71}$ a los usuarios del servicio de mediación con el objeto de valorar su funcionamiento y poder mejorarlo. Las encuestas deben ser anónimas y valoradas periódicamente. Las propias instituciones de mediación pueden disponer de comisiones de control, además de lo que disponga el CGPJ para ello. Ambos documentos se envían al CGPJ para control y elaboración de estadísticas. Para la correcta coordinación esta documentación será remitida al correo electrónico mediacion@cgpj.es o por correo ordinario a la calle Marqués de la Ensenada no8. 28004 Madrid, antes del 10 de Enero y 10 de Julio de cada año correspondiente.

Los juzgados deberán remitir semestralmente al CGPJ los datos de sus registros indicados en el apartado anterior sobre resultados de la mediación. (DOC. 12 GUIA CGPJ). También el letrado de la administración de justicia debe hacer un control de los asuntos derivados a mediación en cada trimestre y los terminados con o sin avenencia.

\footnotetext{
${ }^{67 G u i ́ a ~ d e l ~ C G P J ~ p .62 ~}$
}

68 Ese DOC 12 requiere la información sobre: Juzgado del que procede el asunto, Número de proceso, Identificación del mediador/es, Tema de la controversia: vecindad, división cosa común, sucesiones, familia, sociedades, responsabilidad civil u otros, Fecha de la derivación a mediación, Fecha de inicio de la mediación, Fecha de finalización de la mediación, Resultado de la mediación.

${ }^{69}$ Esta adaptación la realizamos en la experiencia piloto intrajudicial de Huelva, pues facilitaba al mediador la devolución de la información al juzgado debidamente cumplimentada, para que éste proceda con el registro particular de sus datos de casos derivados.

${ }^{70}$ Anexo 6. Ficha estadística es el DOC 14 de la Guía del CGPJ. Hemos tomados plazos del protocolo que hemos elaborado para Huelva que incorpora en panel de mediadores.

${ }^{71}$ Anexo 7 Encuesta de satisfacción DOC. 15 de la guía del CGPJ. 


\section{Bibliografía}

ALASTRUEY GRACIA, Raquel, «Argumentario sobre la búsqueda de soluciones negociadas en el proceso civil». Disponible en http: www.poderjudicial.es.

ALZATE, Ramón, Análisis y resolución de conflictos. Una perspectiva psicológica, UPV, Bilbao, 1998.

BARONA VILAR, Silvia, Mediación en asuntos civiles y mercantiles en España, Tirant lo Blanch, Valencia, 2013.

Bonet Navarro, A. (Dir.), Proceso civily mediación. Su análisis en la Ley 5/2012, de mediación en asuntos civiles y mercantiles, Thomson Reuters Aranzadi, Pamplona, 2013.

BRoOKE, H., "Mediation in the UK today", disponible en http://www.cedr.com.

BuTTS GRIGGS, Thelma, "La mediación en los Estados Unidos: contexto y experiencias", en Cuadernos de Derecho Judicial, Consejo General del Poder Judicial, 2005.

CARretero, Emiliano, La mediación civil y mercantil en el sistema de justicia. Dykinson Madrid, 2016.

Cordón Moreno, F. y SÁnchez Pos, M.V., La Ley de Medidas de Agilización Procesal y la Ley de Mediación: Exposición de las reformas recientes de la Justicia Civil, Thomson Reuters Aranzadi, Navarra, 2012.

Di Stefano, "Mediación conectada con los tribunales: estructuración y principios que regulan su funcionamiento", en SOLETo MuÑoZ, H. (Dir.), Mediación y resolución de conflictos. Técnicas y ámbitos, Tecnos, Madrid, 2011.

FAJARDo MARTOS, Paulino, «La posición del abogado en el proceso de mediación». Disponible en: http://www.congresomediacion.es/pdf/PAULINO\%20FAJARDO.pdf

FERNÁNDEZ MANZANO, M.L., «La calidad de los servicios de mediación: el compromiso ético de las entidades que los gestionan, la supervisión de la labor mediadora y la formación profesional de los mediadores, instrumentos clave para alcanzarla», comunicación presentada en el marco del III Simposio Tribunales y Mediación en España, celebrado en Madrid los días 26 y 27 de septiembre de 2013.Disponible en: http:// www.mediacio- nesjusticia.es.

FonT-GuZMÁn, J., «Programas de derivación judicial en Estados Unidos», en SolETo MuÑOZ, Helena (Dir.), Mediación y resolución de conflictos. Técnicas y ámbitos, 2a ed., Tecnos, Madrid, 2013.

FreIRE PÉREZ, Rosa, «La posición del Juez ante la mediación: ¿Espectador, participante, garante?», en SOLETo MuÑoz, Helena (Dir.), Mediación y resolución de conflictos. Técnicas y ámbitos, Tecnos, Madrid, 2011.

GonZÁLEZ MARTín, L.A., «Aspectos procesales de la Ley de Mediación», Iuris, Actualidad y Práctica del Derecho, 183, enero 2013.

LEDERACH, John Paul, Enredos, pleitos y problemas, una guía práctica para resolver conflictos, Clara Semilla, Colombia, 1985.

LEDERACH, John Paul, «Elementos para la resolución de conflictos» En Revista Educación en Derechos Humanos. no II Noviembre 1990 Uruguay y en Cuadernos de No-violencia, No. 1, SERPAJ, México, 1989.

MARTín DIZ, F., La mediación: sistema complementario de administración de justicia, CGPJ, Madrid, 2010. 
MARTíN DIZ, F., «La Mediación: marco general para su implantación como sistema complementario de Administración de Justicia», en MARTín Diz, F. (Coord.), La mediación en materia de familia y Derecho penal. Estudios y análisis, Andavira, Santiago de Compostela, 2011.

Martín Nájera, T., Pérez Sala- Zar, M. y Utrera Gutierrez, J.L., "Protocolo para la implantación de la mediación familiar intrajudicial en los juzgados y tribunales que conocen de procesos de familia", Revista de Mediación, Año 2, No 4, octubre 2009

MEjÍAS GÓMEZ, J.F., La mediación como forma de tutela judicial efectiva, El Derecho, Madrid, 2009.

MOORE, Cristopher, El proceso de Mediación. Métodos y prácticas para la resolución de conflictos, Granica, Buenos Aires, 1993.

MoRello, L., «Parte la mediazione obbligatoria. Vediamo nel dettaglio come». Disponible en: http://www.diritto24.ilsole24ore.com/civile/civile/primiPlani/2013/09.

MuLDoon, Brian, El corazón del conflicto, Paidós, Barcelona,1998.

Munduate JACA, Lourdes, MEDINA DIAZ, Fco. J., Gestión de conflictos, negociación y mediación, Pirámide, Madrid, 2006.

ORTUÑo MuÑOZ, Pascual, «El papel del abogado en la mediación», Abogados, octubre 2009.

ORTUÑo MuÑoz, Pascual, «La mediación intrajudicial», en LAUROBA, E., BARRAL, I. y Viola, I. (Dirs.), Materiales jurídicos del Libro Blanco de la Mediación en Cataluña, Generalitat de Catalunya, Departament de Justicia, Centre d’Estudis Jurídics i Formació Especialitzada, Barcelona, 2011.

ORTUÑo MuÑoz, Pascual, «A modo de conclusiones: la implantación de la mediación intrajudicial», en Pompeu CASAnovas, Jaume M. y LaurobA M Elena (Dirs.), Libro Blanco de la Mediación en Cataluña, Departament de Justicia de la Generalitat de Catalunya, Barcelona, 2011.

PRESS, S., "Formación de Mediadores y Cualificación - Tribunales del Esta- do de Florida”, en LAUROBA, E., BARRAL, I. y VIOLA, I. (Dirs.), Materia- les jurídicos del Libro Blanco de la Mediación en Cataluña, Generalitat de Catalunya, Departament de Justicia, Centre d’Estudis Jurídics i Formació Especialitzada, Barcelona, 2011

Soleto MuÑOZ, Helena, "El proceso de mediación", en SOLETO MUÑOZ, Helena. (Dir.), Mediación y resolución de conflictos. Técnicas y ámbitos, Tecnos, Madrid, 2011.

SOLETO MUÑOZ, Helena, "La mediación conectada con los tribunales", en SOLETO MUÑOZ Helena. (Dir.), Mediación y resolución de conflictos. Técnicas y ámbitos, $2 \mathrm{a}$ ed, Tecnos, Madrid, 2013.

URY, Willian, FISHER, Roger, PATTON, Bruce, Obtenga el sí: El arte de negociar sin ceder, Gestión 2000, Barcelona, 2011.

VALERo LlORCA, J. y COBAS COBIELLA, M.E., «La responsabilidad del mediador a la luz de la Ley 5/2012, de 6 de julio, de mediación en asuntos civiles y mercantiles. Aproximación a la cuestión», Diario La Ley, No 7987, 19 de diciembre de 2012.

WISSLER, R.L., "Court-Connected Mediation in General Civil Cases: What We Know from Empirical Research", Ohio State Journal on Dispute Resolution, Vol. 17: 32002. 
Zapatero Gómez, J., Sáez Valcárcel, R. y Ortuño Muñoz, P., “Conclusiones”, en Sáez VALCÁRCEL, R. y ORTUÑo MuÑoz, P. (Dirs.), Alternativas a la judicialización de los conflictos: la mediación, CGPJ, Centro de Documentación Judicial, Madrid, 2007.

Ley $1 / 2000$, de 7 de enero, de Enjuiciamiento Civil. Disponible en https://www.boe.es/buscar/doc.php?id=BOE-A-2000-323.

Directiva 2008/52/CE del Parlamento Europeo y del Consejo, de 21 de mayo de 2008, sobre ciertos aspectos de la mediación en asuntos civiles y mercantiles. Disponible en

Directiva 2013/11/UE del Parlamento Europeo y del Consejo de 21 de mayo de 2013, relativa a la resolución alternativa de litigios en materia de consumo. Disponible en http://www.congreso.es/portal/page/portal/Congreso/Congreso/Publicaciones

Sentencia del Tribunal de Justicia Europeo de 14 de junio de 2017 Tribunal de Justicia de la Unión Europea, Sala Primera, Sentencia de 14 Jun. 2017, C-75/2016, № de Recurso: C-75/2016, Disponible en http://curia.europa.eu/juris/document/document.jsf;jsessionid=9ea7d0f130d577 754f5834644e608124fe908d8cfbd3.e34KaxiLc3eQc40LaxqMbN4PaN80e0?text= \&docid=191706\&pageIndex=0\&doclang=ES\&mode=req\&dir=\&occ=first\&part=1\& cid $=884599$.

Ley 5/2012 de Mediación para asuntos civiles y mercantiles. Disponible en https://www.boe.es/buscar/act.php?id=BOE-A-2012-9112.

Real Decreto 980/2013, de 13 de diciembre que desarrollo algunos aspectos de la LEY 5/2012 de mediación para asuntos civiles y mercantiles. Disponible en http://www.boe.es/buscar/doc.php?id=BOE-A-2013-13647.

Guías para la práctica de la mediación intrajudicial publicadas por el CGPJ. Disponible en http://www.poderjudicial.es/cgpj/es/Temas/Mediacion/Guia-para-la-practicade-la-Mediacion-Intrajudicial/

Proyecto de Ley por la que se incorpora al ordenamiento jurídico español la Directiva 2013/11/UE del Parlamento Europeo y del Consejo de 21 de mayo de 2013, relativa a la resolución alternativa de litigios en materia de consumo. Boletín Oficial de las Cortes Generales de 31 de julio de 2017. Congreso de los diputados XII Legislatura. Disponible en http://www.congreso.es/portal/page/portal/Congreso/Congreso/Publicaciones/. Servicios de mediación intrajudicial registrados por el CGPJ. Disponible en http://www.poderjudicial.es/cgpj/es/Temas/Mediacion/Servicios-de-MediacionIntrajudicial/.

Convenios del CGPJ por Jurisdicción, Comunidad Autónoma, provincia y entidades http://www.poderjudicial.es/cgpj/es/Temas/Mediacion/Convenios/.

Convenio de colaboración para promoción de la mediación entre CGPJ y las CCAA. En http://www.juntadeandalucia.es/export/drupaljda/Convenio\%20de\%20colabora ción\%20para\%20la\%20promoción\%20de\%20la\%20mediación\%20(2).pdf.

Convenio marco de colaboración del CGPJ y CGAE. Disponible en http://www.justicia.gva.es/documents/19317797/163996221/ConvenioMediacion-Abogacia-CGPJ.pdf/38e50620-ccab-4175-98b4-ded236881ac8. 
Ministerio de Justicia, sitio web del registro de mediadores http://www.mjusticia.gob.es/cs/Satellite/Portal/es/areastematicas/registros/mediadores-instituciones.

\section{Anexos del protocolo de derivación}

Los anexos que acompañan este trabajo han sido creados y adaptados para la operatividad del panel ${ }^{72}$. Con ellos los mediadores e instituciones de mediación pueden solicitar su inclusión en el panel intrajudicial de mediadores (anexo 1) y facilitar la información necesaria además de su conformidad a formar parte del panel intrajudicial (Anexos 2 y 3 ) por lo que resultan de obligada cumplimentación y entrega al órgano judicial. El resto de los anexos son documentos incorporados a las Guías para la práctica de la mediación intrajudicial del CGPJ (Anexos 4,5,6,7), si bien en algunos hemos introducido algunas modificaciones. Los anexos 1, 2 deben ser presentado por todo mediador, bien directamente al lugar habilitado por los juzgados para su presentación o bien a través de la institución de mediación a la que pertenezca. Ésta, deberá apórtalos junto a la Ficha Registro de Instituciones de mediación (Anexo 3) en sede judicial.

ANEXO 1. Modelo normalizado de solicitud de acceso al Panel de Mediadores para Instituciones y Mediadores.

ANEXO 2. Modelo de CV a cumplimentar por todos los mediadores del panel intrajudicial.

ANEXO 3. Modelo de ficha de acceso de las Instituciones de mediación al panel de mediadores.

ANEXO 4. Modelo de ficha de derivación a Información/Sesión Informativa de mediación (anverso) e información de resultados de la misma (reverso). (DOC. 12)

ANEXO 5. Panel de mediadores intrajudiciales a efecto de información para jueces y oficina judicial.

ANEXO 6. Modelo de recogida de datos estadísticos obligatorio para los mediadores (Doc. 13)

ANEXO 7. Modelo obligatorio para mediadores de encuesta de satisfacción (Doc. 14)

\footnotetext{
72 En el correo electrónico info@mediadorintrajudicial.com le facilitaremos los anexos que no están en la guía del CGPJ así como el protocolo de actuación elaborado para los juzgados de Huelva.
} 
ANEXo 1. SOlicitud DE ACCESO AL PANEL DE MEDIADORES INTRAJUdiciales DE MEDIADORES/ENTIDAD/COLEGIO PROFESIONALES DE LOS JUZGADOS DE LA PROVINCIA DE HUELVA

\author{
1. DATOS DEL SOLICITANTE \\ Nombre y apellidos \\ Domicilio (a efectos de notificación) \\ Número del documento nacional de identidad (DNI) \\ $\mathrm{N}^{\mathrm{o}}$ de teléfono de contacto \\ Correo electrónico \\ En nombre y representación de la entidad \\ $\mathrm{CIF} / \mathrm{NIF}$ \\ Domicilio (a efectos de notificación) \\ $\mathrm{N}^{\circ}$ de teléfono de contacto \\ Correo electrónico
}

\title{
2. DATOS RELATIVOS A LA SOLICITUD
}

Deseo incorporarme al Panel de Mediadores/Instituciones de Mediación Intrajudicales en los Juzgados de Huelva, en

En los partidos judiciales de:

En la/las Jurisdicción:

Desea participar en las sesiones de información que se desarrollen en el PIMED (Punto de Información a la Mediación de la Junta de Andalucía (SI / NO)

Acepta participar de la derivación de asuntos con derecho a justicia gratuita (SI / NO):

A esta solicitud se acompañan los siguientes documentos preceptivos:

A. Copia de acredite su inscripción en el registro de mediadores del Ministerio de Justicia

B. Modelo de CV normalizado al efecto

C. Las instituciones de mediación deben remitir el modelo de CV de todos los mediadores que quieran incorporarse al panel de mediadores intrajudiciales.

El/la abajo firmante, SOLICITA su inclusión en el panel de mediadores/institución mediadora intrajudicial de los tribunales de justicia de Huelva, DECLARA que son ciertos los datos consignados en ella y AUTORIZA a la administración de justicia a incorporar los datos a los protocolos correspondientes, así como a la PUBLICIDAD de los mismo a través del Panel de mediadores. Y manifiesta su compromiso para ser designado mediador:

LUGAR Y FECHA

FIRMA

Ver instrucciones de cumplimentación al dorso 


\section{INSTRUCCIONES PARA CUMPLIMENTAR EL IMPRESO}
A. EL DOCUMENTO DEBERÁ CUMPLIMENTARSE CON LETRAS MAYÚSCULAS, SIN ENMIENDAS NI TACHADURAS.
B. LOS SOLICITANTES DEBEN CUMPLIMENTAR RIGUROSAMENTE LA SOLICITUD Y EL MODELO DE CV.

\section{1.- DATOS DEL SOLICITANTE:}

A. Nombre y apellidos: Se indicará el nombre y los apellidos completos del solicitante.

B. Número de documento nacional de identidad (DNI) o número de identidad de extranjero (NIE), CIF/ NIF para instituciones

C. $\mathrm{N}^{\circ}$ de teléfono de contacto: Se indicará el número de teléfono del solicitante. Y en su caso también de la institución de mediación.

D. -e indicará el tipo de vía pública (avda., calle o plaza), con la denominación y número que corresponda al primer domicilio de notificación.

E. Localidad: Se señalará la localidad correspondiente al domicilio.

F. Código postal: Se consignarán los dígitos correspondientes al código postal del domicilio indicado.

G. Provincia y país: Se indicarán la provincia y el país a que pertenece el domicilio indicado.

H. En el supuesto de que se quiera facilitar un segundo domicilio de notificación, se seguirán las mismas instrucciones de cumplimentación.

\section{2.- DATOS RELATIVOS A LA SOLICITUD:}

Deseo incorporarme al Panel intrajudicial de mediadores/instituciones de mediación en los Juzgados de Huelva en:

En los partidos judiciales de: HUELVA CAPITAL, AYAMONTE, LA PALMA, MOGUER, ARACENA, VALVERDE

En la/las jurisdicción: CIVIL, MERCANTIL, PENAL, SOCIAL, CONTENCIOSO

\section{DOCUMENTOS PRECEPTIVOS:}

- Documento que expide el ministerio tras proceder a la inscripción con su número correspondiente

- Modelo de curriculum vitae (Anexo2) que se adjunta a esta solicitud, o bien la institución de mediación (Anexo 3) que adjunta un cv por cada mediador.

- El interesado debe especificar su disposición para asumir sin costes la derivación de asuntos de justicia gratuita, especificando sí o no

- El interesado debe especificar su disposición para participar en las sesiones de información que se desarrollan en el punto de información a la mediación de la CCAA especificando sí o no

LUGAR Y FECHA: Se indicará el lugar y fecha en que se cumplimenta el impreso.

FIRMA: Se firmará el impreso de solicitud. 


\section{ANEXo 2}

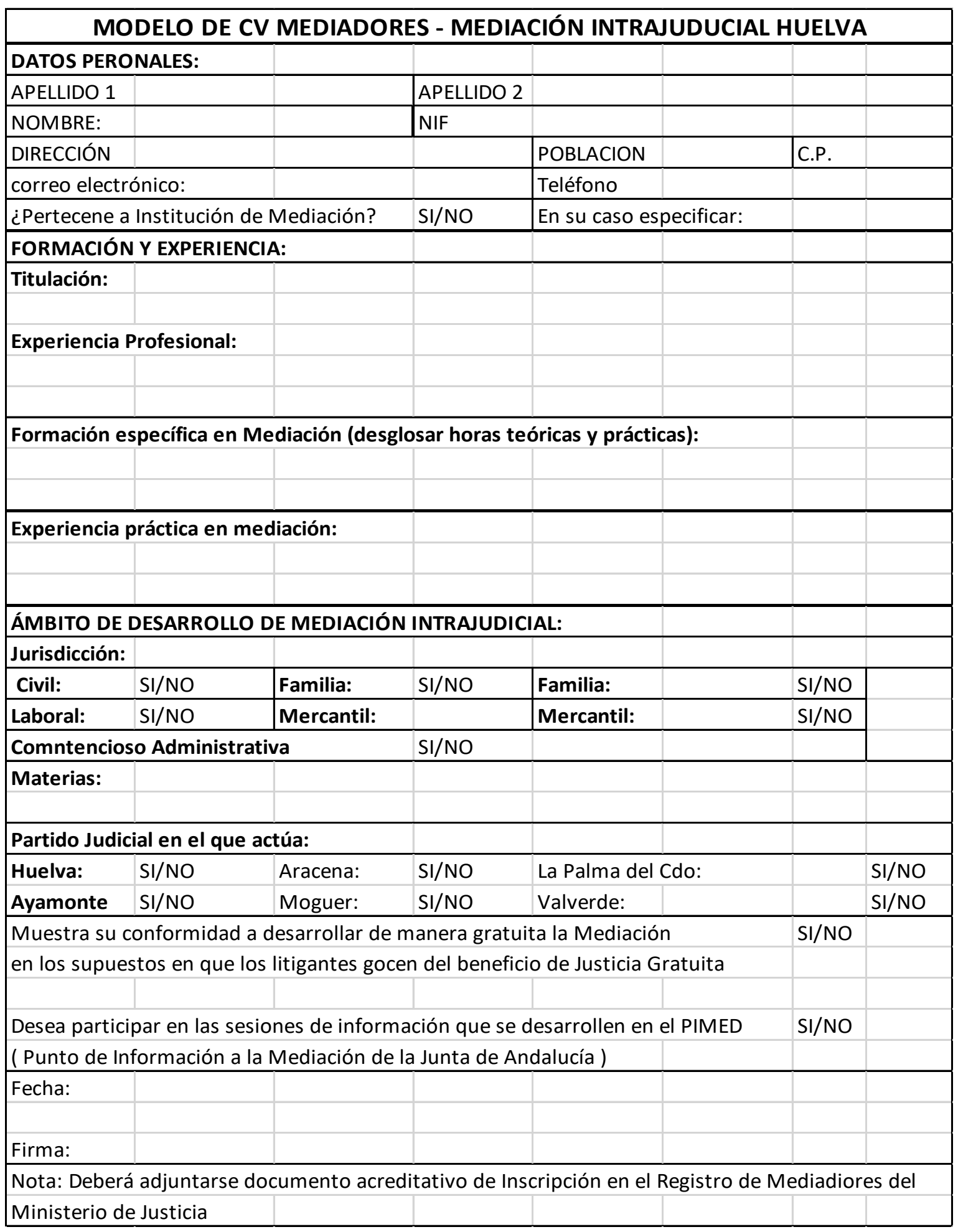


ANEXo 3

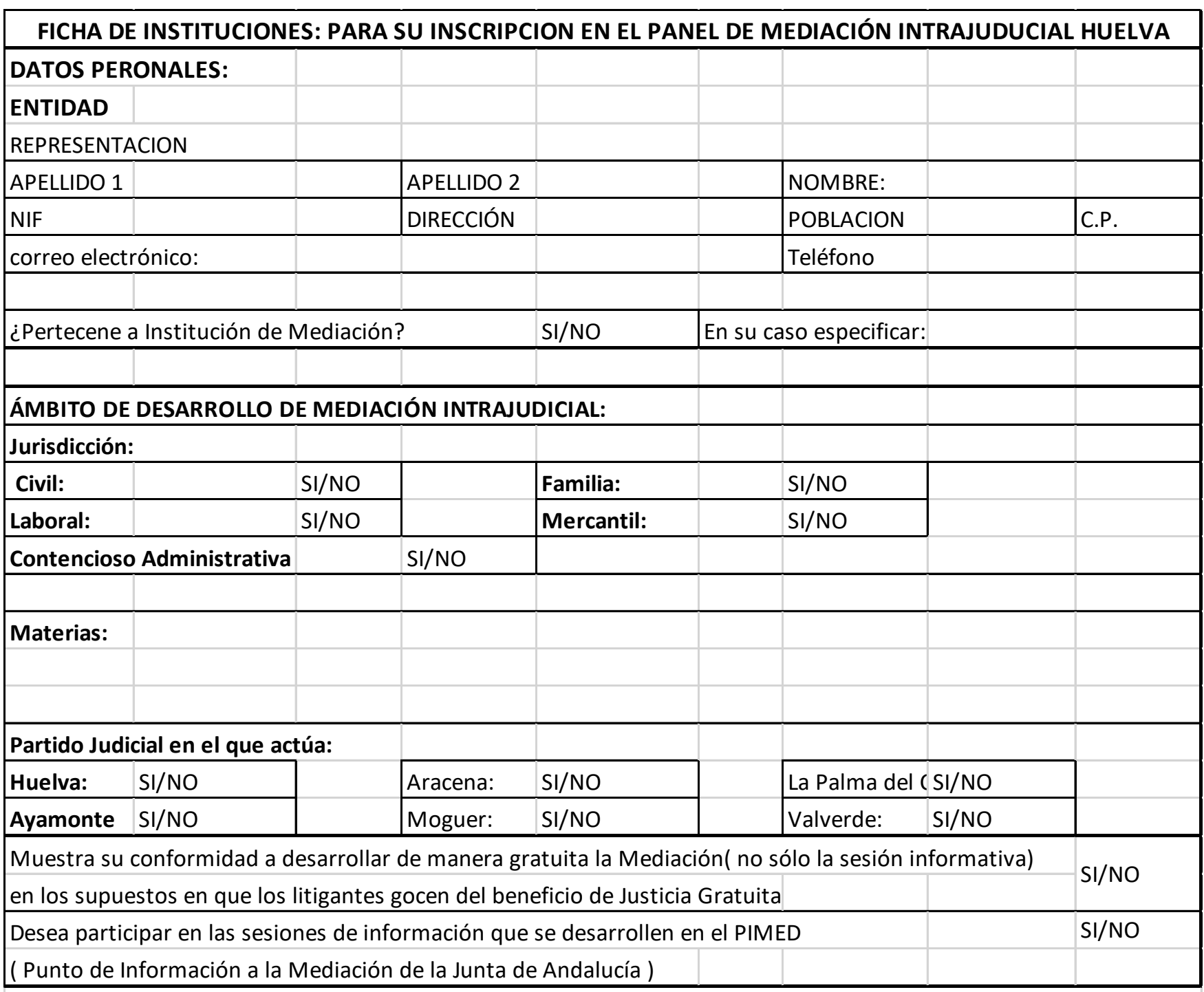

SE DEBE ADJUNTAR A LA PRESENTE EL MODELO NORMALIZADO DE CURRICULUM DE LOS MEDIADORES EN ELLA INSCRITOS QUE PARTICIPARAN EN LA MEDIACION INTRAJUDICIAL Y CUMPLEN LAS EXIGENCIAS DE LA LEY 5/2012 DE MEDIACION PARA ASUNTOS CIVILES Y MERCANTILES

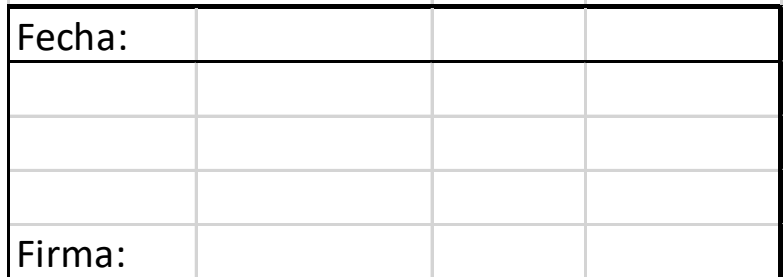

Nota: Deberá adjuntarse certificado de Inscripción en el Registro de Mediadores del Ministerio de Justicia. 